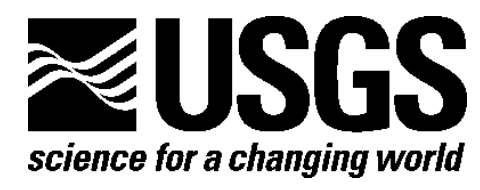

\title{
Serious Games Experiment toward Agent-based Simulation
}

By Anne Wein and William Labiosa

Open File Report 2013-1152

U.S. Department of the Interior U.S. Geological Survey 


\section{U.S. Department of the Interior \\ SALLY JEWELL, Secretary}

\section{U.S. Geological Survey}

Suzette M. Kimball, Acting Director

U.S. Geological Survey, Reston, Virginia: 2013

For more information on the USGS-the Federal source for science about the Earth, its natural and living resources, natural hazards, and the environment-visit http://www.usgs.gov or call 1-888-ASK-USGS

For an overview of USGS information products, including maps, imagery, and publications, visit $h$ ttp://www.usgs.gov/pubprod

To order this and other USGS information products, visit http://store.usgs.gov

Suggested citation:

Wein, Anne, and Labiosa, William, 2013, Serious Games Experiment toward Agent-based Simulation: U.S. Geological Survey Open File Report 2013-1152, 30p.

Any use of trade, firm, or product names is for descriptive purposes only and does not imply endorsement by the U.S. Government.

Although this information product, for the most part, is in the public domain, it also may contain copyrighted materials as noted in the text. Permission to reproduce copyrighted items must be secured from the copyright owner. 


\section{Contents}

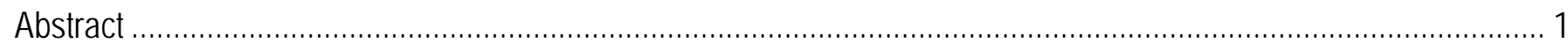

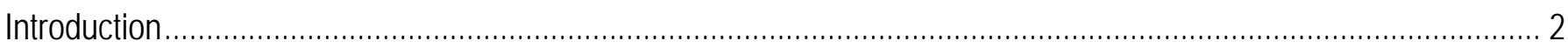

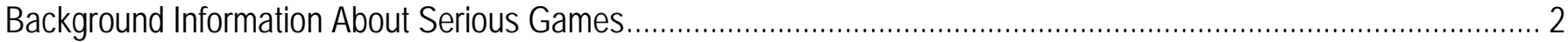

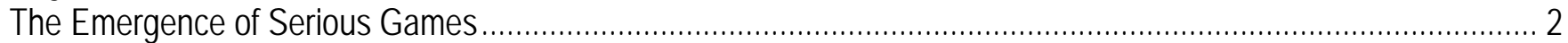

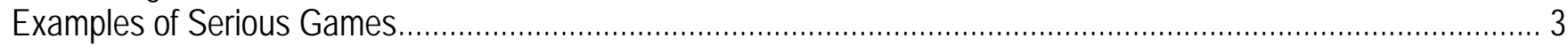

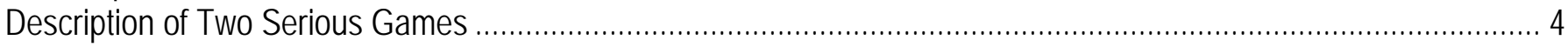

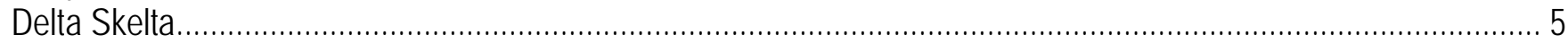

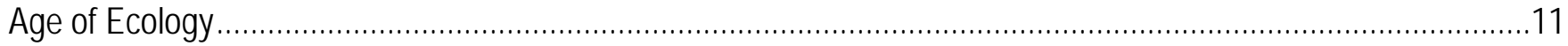

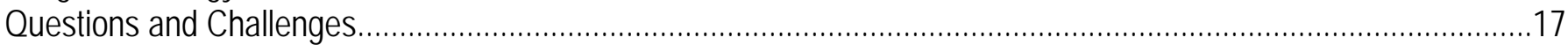

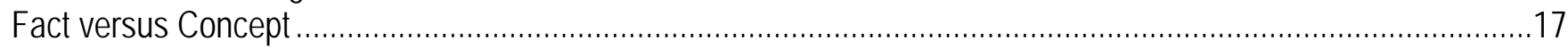

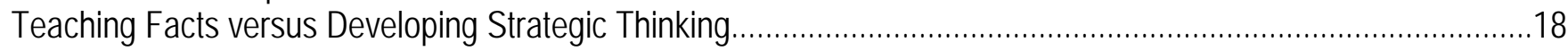

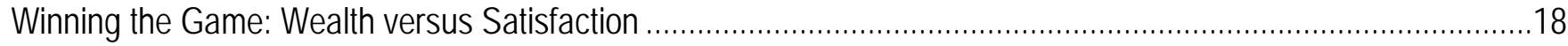

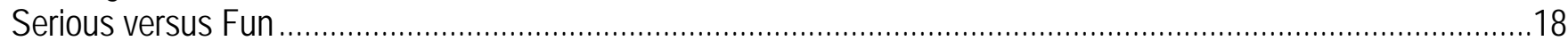

Games for the Uninitiated Player versus the Gamer ..............................................................................

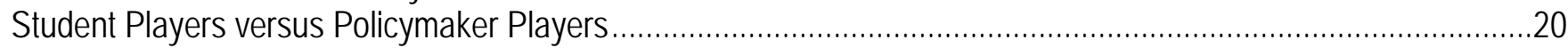

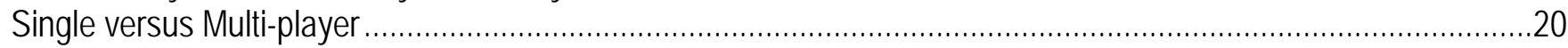

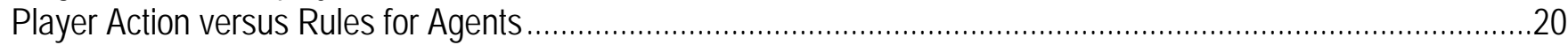

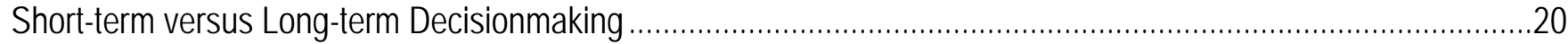

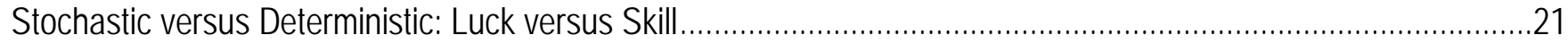

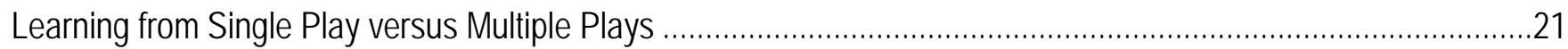

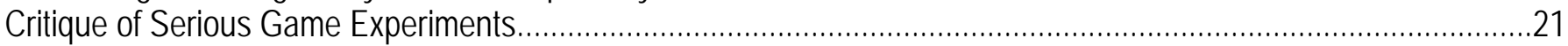

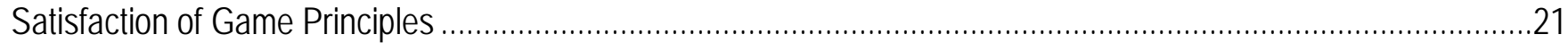

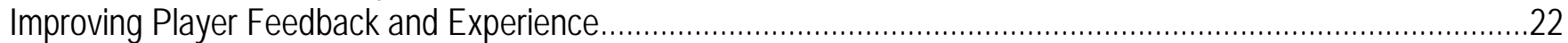

Representation of Complex Geological, Ecological, and Economic Systems …….............................................22

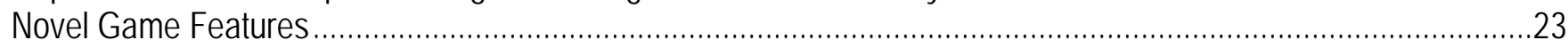

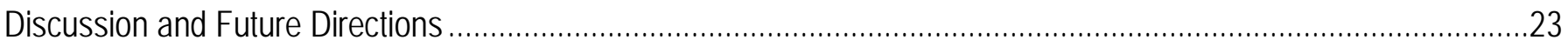

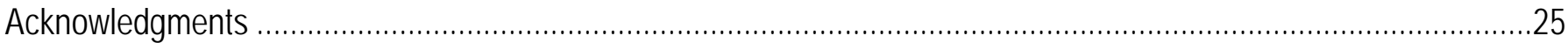

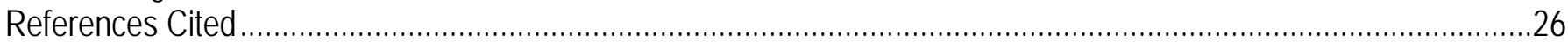

Appendix: List of Sacramento-San Joaquin Delta Issues .............................................................................

\section{Figures}

Figure 1. An influence diagram (or decision diagram) of the Delta Skelta game. The red rectangle (Investments \& Policies) depicts the set of decision choices made by the player or Mayor, ovals depict uncertain variables whose successive states are observed as the game proceeds, and the red hexagon depicts the player's success in maintaining the satisfaction of stakeholders, the object of the game. Stakeholders' satisfactions are functions of resources and revenues that are affected by (1) player land use and waterallocation policies and investments in the delta infrastructure, and (2) other external factors including earthquake occurrences, climate change and sea-level rise, population growth, and crop prices.

Figure 2. Delta Skelta game map with left panel displaying geographical attributes for the yellow highlighted agricultural region. Attributes include water allocations, crop information, revenue, and ecological health. The status of best management practices depends on the player's choice to enforce or not. Similarly, players can access information and options for natural areas (green) and developed regions (red). The dial on the map monitors overall stakeholder satisfaction. 
Figure 3. Delta Skelta game map with a levee highlighted by light blue outline (in yellow box). Left panel displays attributes of the levee condition. Player can select to inspect, upgrade, or remove the levee.

Figure 4. Delta Skelta players monitor the success based on the satisfaction of the four stakeholder groups.......... 9

Figure 5. Graph of water exports over time presents an example of monitoring a Delta Skelta game variable over time.

Figure 6. Following an earthquake (epicenter marked with red bull's eye), the Delta Skelta player may inspect levees and receive a levee-vulnerability alert.

Figure 7. Each Age of Ecology game board is a randomly generated landscape and topography. Age of Ecology

players use the paint brush tool to select land for purchase. ....................................................... 12

Figure 8. On city land, players enable industries (the pink area), upgrade infrastructure, and invest in earthquake protection. Similarly, on agricultural land, players invest in crops for rotation (the yellow, green, and orange pixels). This and the subsequent game board (fig. 9) shows a randomly generated landscape. . 13

Figure 9. Age of Ecology players construct ports and invest in fishing boats and nets.

Figure 10. Diagram of Age of Ecology game. Fish, city, farm, and natural components contain player controlled decisions and autonomously simulated agents. Random simulated events of crop failure, flood, and earthquake occur that can be mitigated by farm crop, and hazard protection decisions. Player decisions and simulated agents interact, culminating in profits (represented by the green triangle) that measure player success.

Figure 11. Players can monitor the environment in the Age of Ecology by displaying layers of information such as water pollution, indicated above in shades of gray.

Figure 12. The player monitors the fish population in the Age of Ecology game. Depleted stocks are indicated by blue shading in the water bodies. The figure also displays agent-based crop rotations in orange, green, and yellow fields. The blue industrial area represents the professional-services sector.

Figure 13. The Age of Ecology player can display the current distribution of game profits from agriculture and industry.

Figure 14. Prior to playing the game, Age of Ecology players adjust the difficulty, length, and speed of the game. More difficult games have a lower environmental resilience and (or) more frequent occurrences of natural disasters. 


\title{
Serious Games Experiment toward Agent-based Simulation
}

\author{
By Anne Wein and William Labiosa
}

\begin{abstract}
We evaluate the potential for serious games to be used as a scientifically based decision-support product that supports the United States Geological Survey’s (USGS) mission-to provide integrated, unbiased scientific information that can make a substantial contribution to societal well-being for a wide variety of complex environmental challenges. Serious or pedagogical games are an engaging way to educate decisionmakers and stakeholders about environmental challenges that are usefully informed by natural and social scientific information and knowledge and can be designed to promote interactive learning and exploration in the face of large uncertainties, divergent values, and complex situations. We developed two serious games that use challenging environmental-planning issues to demonstrate and investigate the potential contributions of serious games to inform regional-planning decisions. Delta Skelta is a game emulating long-term integrated environmental planning in the Sacramento-San Joaquin Delta, California, that incorporates natural hazards (flooding and earthquakes) and consequences for California water supplies amidst conflicting water interests. Age of Ecology is a game that simulates interactions between economic and ecologic processes, as well as natural hazards while implementing agent-based modeling. The content of these games spans the USGS science mission areas related to water, ecosystems, natural hazards, land use, and climate change. We describe the games, reflect on design and informational aspects, and comment on their potential usefulness. During the process of developing these games, we identified various design trade-offs involving factual information, strategic thinking, game-winning criteria, elements of fun, number and type of players, time horizon, and uncertainty. We evaluate the two games in terms of accomplishments and limitations. Overall, we demonstrated the potential for these games to usefully represent scientific information within challenging environmental and ecosystem-management contexts and to provide an interactive way of learning about the complexity of interactions between people and natural systems. Further progress on the use of pedagogical games to fulfill the USGS mission will require collaboration among scientists, game developers, educators, and stakeholders. We conclude that as the USGS positions itself to communicate and convey the results of multiple science strategies, including natural-resource security and sustainability, pedagogical game development and agent-based modeling offer a means to (1) establish interdisciplinary and collaborative teams with a focused integrated outcome; (2) contribute to the modeling of interaction, feedback, and adaptation of ecosystems; and (3) enable social learning through a broadly appealing and increasingly sophisticated medium.
\end{abstract}




\section{Introduction}

Education and training are common goals of serious game usage, and these games are potentially an engaging way to educate about problems that are informed by complex scientific data and theory and that include large uncertainties and conflicting values. Formal definitions of serious games range from “digital games that are used for purposes other than mere entertainment” (Susi and others, 2007) to "a simulation which has the look and feel of a game, but is actually a simulation of real-world events or processes of real-world events" (Sawyer, 2002). Although there is no single definition of a serious game and there are many possible purposes for serious-game creation and usage, their ability to incorporate simulations within an engaging problem-solving context is intriguing. They are well-suited to accommodating simulated scientific processes that interact with societal and resource-management decisionmaking processes. Although serious games have undergone significant technological advancement and much has been learned from using them in practice (Susi and others, 2007), they have seen little usage within the USGS. We postulate that serious games can catalyze the USGS mission to facilitate scientifically based decision-support responsibilities by integrating research that demands interdisciplinary research necessary to delivering scientific understanding and interactive learning about complex problems.

During the summers of 2007 and 2008, we experimented with serious-game design and development with three objectives in mind:

1. To explore serious games as a potential information medium for addressing integrated naturalscience questions that straddle multiple USGS science strategy themes (for example, water, ecosystem, climate change, and natural hazards).

2. To demonstrate how resource-management problems can be posed as games that are informative and fun to play.

3. To implement agent-based modeling, a computer game modeling technique that represents interdependencies, feedback, and adaptations of ecosystem components.

To the best of our knowledge, the work reported here is the first attempt to demonstrate the potential use of serious games within the USGS, although, numerous Government applications of serious gaming exist today. In particular, military-training serious games enable players to experience otherwise rare and unsafe situations. Other training games prepare players at various levels of government (municipal, State, and national) for terrorist attacks, disease outbreaks, biohazards, healthcare policy planning, city planning, traffic control, transportation planning, firefighting, budget balancing, project management, ethics training, and defensive driving (Susi and others, 2007; Michael and Chen, 2006). The United States Department of Transportation, Federal Highway Administration (FHA) uses serious games as a public-involvement technique for transportation decisionmaking (United States Department of Transportation, Federal Highway Administration, 2008).

\section{Background Information About Serious Games}

\section{The Emergence of Serious Games}

Serious game development is a new field that took off in 2002 with the release of America's Army (United States Department of the Army, 2012). The serious-game movement emerged in the same year with the Serious Games Initiative founded by the Woodrow Wilson Center (Susi and others, 2007). The Woodrow Wilson Center announced the mission of creating "a better understanding of how 
commercial game and simulation developers, practices, and technology can be utilized by a wider field of organizations that build and apply models and simulations in the area of public policy.” Because models and simulations are already used in policymaking "to affect the education, debate, and implementation process for a variety of initiatives, can we take advantage of the state of the art within the interactive entertainment industry to elevate learning-especially strategic thinking” (Sawyer, 2002). Three contributions from the game industry to this arena were identified as (1) pioneering expertise in artificial intelligence and agent-based modeling (owing to practical experience of creating challenging opponents and believable in-game characters), (2) interface design, and (3) expression of the essence of complex problems in a form that encourages others to explore that complexity. The latter is attributed to the creative force that drives most game developers and makes them natural out-of-the box thinkers, as well as excellent observers of the world around them. This sort of world-building motivation is especially useful for creating models of complex systems (Sawyer, 2002). Squire and Jenkins (2003) observe that some of the most successful game franchises-Civilization, SimCity, Railroad Tycoon - have demonstrated how games can model complex social, scientific, and economic processes. Their designers are explicit about the degree to which the games are based on significant new theories of how cities work, or how civilizations evolved.

Sawyer (2002) further advocates that "gaming builds on basic instincts for competition, interaction, and imagination that are instinctive to so many people.” Game-playing can amplify observation and learning, including learning from mistakes without dire consequences, encouraging creative and strategic thinking, and extensive exploration of possible solutions and hypothesis testing. For these reasons, games show great promise as vehicles for serving up complex information to students and planners and their stakeholders in a form that encourages repeated exposure and exploration (Sawyer, 2002; Squire and Jenkins, 2003).

Serious games show great promise as an alternative means for society to assimilate scientific information and, specifically, to understand, explore, and interact with the complexities of economic, hydrologic, and ecologic systems and geologic processes. These aspects align with the USGS sciencestrategy themes of water, ecosystems, climate change, and natural hazards, and can be integrated through land-use and land-cover change (United States Geological Survey, 2007). We were further encouraged by the promise that, ultimately, serious games stimulate inquiry, are useful for evaluating alternatives and trade-offs, and may even inform policymaking.

\section{Examples of Serious Games}

We gleaned ideas and formed expectations from reading about or playing other commercially successful games, government games, and games related to USGS science-strategy themes. A popular relevant example is SimCity, a city-building simulation that includes complex feedback, conflicting goals, and constraints that has moved beyond a focus on resource allocations to consideration of natural hazards and climate change.

In the Government games section of Michael and Chen (2006) and at government Web sites, we discovered serious computer games developed for various purposes.

1. Examples of games to educate include

- The Department of Education's Creature Control: The Quest for Homeostasis (United States Department of Education, [n.d.]) for middle school students.

- The Department of Commerce’s Where Rivers Meet the Sea (National Oceanic and Atmospheric Administration, 2009) for middle school students. 
2. Examples of training games include

- The Department of Justice’s Quandaries (United States Department of Justice, 1998), an ethics training tool for Federal employees.

- The Federal Aviation Administration's advanced simulations to train air traffic controllers.

- The Department of Agriculture's 3D Wild Land Fire Simulation (National Fire Academy, United States Forest Service, [n.d.]), a fire-fighting game extension of National Fire Academy Training Simulation, incorporating more precise scientific information, such as regional/local fire growth and propagation based on fuel types, environmental conditions, and terrain topology.

3. Examples of games used to inform policymaking include

- Corridor, (Abt, 1970) which was used to inform transportation policy in the Northeast.

- SimHealth (Maxis, 1994) (built on an old DOS platform) was created to facilitate the Clinton administration's health-care reform and apparently used by the White House, politicians, academics, consultants, and the general public. Descriptions of the game suggest that players were put in control of the complex U.S. health-care system and had to deal with balancing needs, controlling costs, financing sources, and their own values.

4. Examples of games that have incorporated natural-science information include

- Disaster Dynamics: Hurricane Landfall (National Center for Atmospheric Research (NCAR), University Corporation for Atmospheric Research (UCAR), 2006), which focuses on the rebuilding and recovery process following a hurricane. It has a voting function to address the fundamental activity of the game for people to learn to make proposals, negotiate, and vote until they run out of funding.

- FloodRanger (Office and Science and Technology in the UK, 2005) is a flood-management game with climate-change scenarios aimed at flood-defense practitioners, local authorities, insurers, universities, and schools. It is funded by the Office and Science and Technology in the United Kingdom and it is a joint project between Discovery Software, Ltd., and View the World, Ltd.

- Environmental Detectives (Massachusetts Institute of Technology (MIT), [n.d.]), developed in MIT's Teacher Education Program, is a scientifically grounded training game using mobile technology that is a role play of a scientific investigation of a hazardous spill.

We found other examples of serious games, but it was more difficult to ascertain frequency of use and effectiveness of these games relative to their intended purpose. Although, Squire and Jenkins (2006) report that historical games, such as Civilization III (Firaxis Games, 2001), are on the market and are already being deployed in classrooms around the country. Furthermore, learning-assessment models are increasingly being embedded in games (for example, Shaffer, 2006; Hatfield, 2011; Gee and Shaffer, 2010). With our curiosity piqued we embarked on developing two serious games.

\section{Description of Two Serious Games}

We initiated the development of each serious game with a concept of choosing a resourceplanning/management problem that included societal trade-offs between risk reductions and other planning goals. We worked with two high school students for five-week periods during the summers of 2007 and 2008. The two students, experienced with and passionate about creating computer games for 
entertainment purposes, provided the necessary game development and programming expertise. The students had internalized many of the principles of game making after many years of playing and creating computer games.

We created two serious games:

- Delta Skelta is a game emulating long-term planning in the Sacramento-San Joaquin Delta, California, incorporating natural hazards (flooding and earthquakes) and consequences for California water supplies amidst conflicting water interests.

- Age of Ecology is a game about regional development and sustainability that depicts interactions between economic and ecologic processes, as well as hazards using agent-based modeling. The content of the games spans issues related to water, ecosystems, natural hazards, land-use, and climate change.

In this section, we use Sawyer's synopsis outline for developer recruiting (Sawyer, 2002, table 1.1) as guidance to describe the games. In addition, we address three other game dimensions of player interface, player actions, and computer actions, and game feedback.

\section{Delta Skelta}

Delta Skelta is a game set in the Sacramento-San Joaquin Delta that was motivated by the debate on alternative futures for the delta (for example, Lund and others, 2007) and the Governor's blue ribbon task force that was set up to evaluate alternatives for 50-, 100-, and 200-year time horizons to address water, land-use, environmental, and institutional elements (Delta Vision, 2008). Land-use and watermanagement tensions in the delta are portrayed by Trott (2007) and the threat of subsidence to water quality is discussed by Ingebritsen and others (2000). Historically, a low level of awareness of regional flood risk and floodplain changes (related to levees) among delta residents has resulted in continued development with low rates of flood insurance and a false sense of security (Fridirici, 2007). The flood threat in the delta area is further exacerbated by the presence of seismic activity and the possibility of levee failure with potentially catastrophic outcomes.

The purposes of the Delta Skelta game are:

1. To educate the player about complex trade-offs between risk and adaptive change related to water resources, ecological resources, flood risks, and other societal issues in the SacramentoSan Joaquin Delta, and trade-offs between risk and adaptive change; and

2. To demonstrate how computer games can simulate real-life policy decisions in a simple way for use in collective problem exploration and strategy development.

Delta Skelta depicts the Sacramento-San Joaquin Delta, a water system that provides water to approximately two of every three Californians, supplies water to one of the Nation's most productive agricultural regions, and provides habitat for endangered and threatened fish species in a variable salinity regime. The delta's future, however, is uncertain owing to:

1. Sea-level rise, storms, subsidence, variable maintenance costs, and earthquakes that threaten the aging levee system;

2. A significant flood/drought cycle exacerbated by sea-level rise;

3. A constant need for low-salinity water for agricultural pumping and water irrigation needs conflicting with the adaption of endangered fish species to varying seasonal salinity cycles; 
4. Population growth creating pressure for continued development and conversion of land to urban uses, thereby, increasing the flood risk from levee failure and degrading environmental health; and

5. The potential for a major earthquake in the region and related levee failure threatens to significantly impact not only the millions of residents in the delta, but also to disrupt a large portion of the water supply for southern California.

In addition, the cities of Stockton, Antioch, and Tracy (among others) in the region increase the importance of making good decisions about the delta's future. In summary, we represent the many interests at stake by using four identified special-interest groups: fish, farms, cities, and southern California (through water exports). A representation of the problem is sketched out in an influence diagram (fig. 1). The investments and policies pertain to the delta system and involve levee maintenance and water-allocation decisions. Delta Skelta attempts to emulate complexity of the region in order to educate players about what is at stake and to encourage them to explore possible futures for this vulnerable area. The four special- interest groups are represented, and their needs must be met over a 50-year planning horizon.

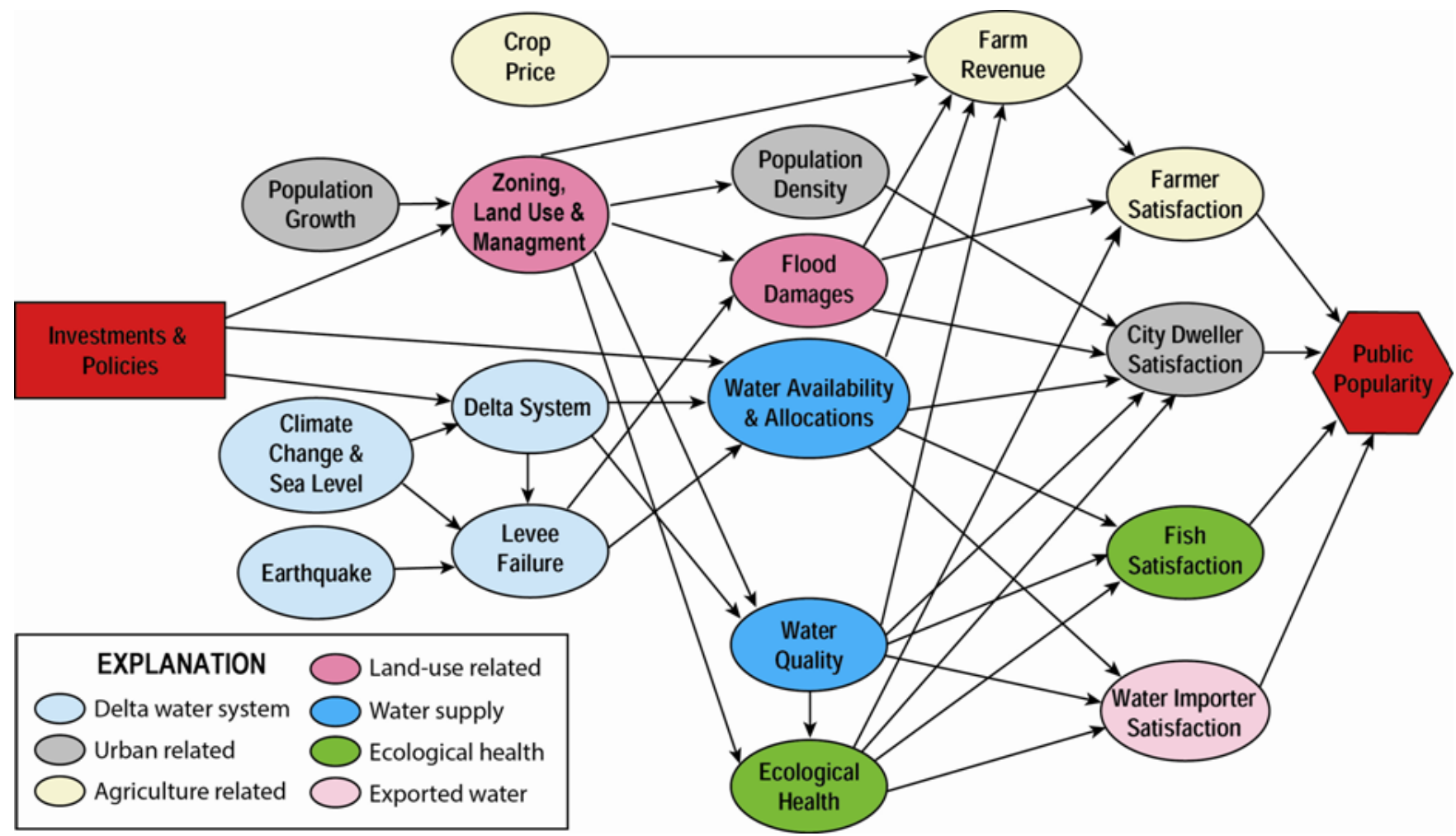

Figure 1. An influence diagram (or decision diagram) of the Delta Skelta game. The red rectangle (Investments \& Policies) depicts the set of decision choices made by the player or Mayor, ovals depict uncertain variables whose successive states are observed as the game proceeds, and the red hexagon depicts the player's success in maintaining the satisfaction of stakeholders, the object of the game. Stakeholders' satisfactions are functions of resources and revenues that are affected by (1) player land use and water-allocation policies and investments in the delta infrastructure, and (2) other external factors including earthquake occurrences, climate change and sea-level rise, population growth, and crop prices. 
Main and ancillary target users of Delta Skelta are high-school level students and beyond. The player's goal, as a county planner, is to keep all four interest groups (farmers, city dwellers, fish, and water importers) satisfied by using strategic investments and polices subject to a budget. To win the game, the player needs to avoid getting voted out of office (that is, maintain the scores from each of the interest groups within upper and (or) lower bounds during the 50-year time horizon).

The Delta Skelta player interface is a stylized map of the delta islands and surrounding land and water-resource districts (tracts). Each land tract has a land use (natural, agricultural, or developed) and associated attributes, including the presence of essential infrastructures (for example, power and gas lines and highways). For an illustration, see figure 2, a screenshot of the interface display of an agricultural tract.

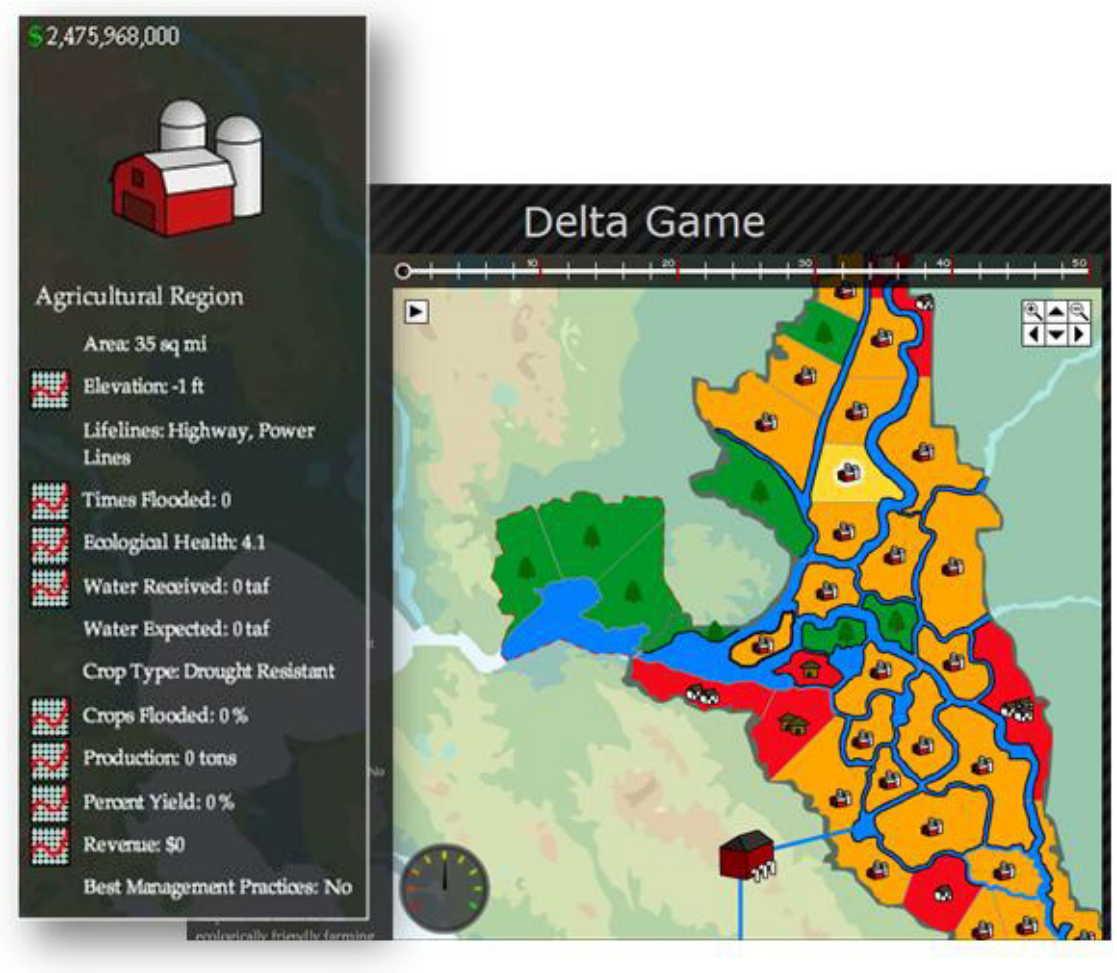

Figure 2. Delta Skelta game map with left panel displaying geographical attributes for the yellow highlighted agricultural region. Attributes include water allocations, crop information, revenue, and ecological health. The status of best management practices depends on the player's choice to enforce or not. Similarly, players can access information and options for natural areas (green) and developed regions (red). The dial on the map monitors overall stakeholder satisfaction.

Player decisions take place in 10-year planning phases, a time when the game stops to allow the player to make major planning decisions. Real-time decisionmaking occurs when the player views and responds to events (such as flooding and levee failure). The player uses the mouse to click on particular land tracts to make changes in land-use designations, such as rezoning a natural area as an agriculture area, or rezoning an agricultural area as a development area, or restoring agricultural land to a natural state. The player clicks on levees to build, inspect, upgrade, and repair levees to protect agricultural and developed regions. Another game action allows the building of a seawall that physically separates fresh 
water bodies from saline water bodies by creating a flow barrier (seaward salt barrier). The computer software simulates salinity and sea-level rise and calculates water delivery and satisfaction scores for the four interest groups, which may have conflicting water-management goals regarding salinity and flow. Various levels of game feedback are provided to the player in the forms of:

1. Summary statistics for each land-use region, levee, and water region (figs. 2 and 3).

2. An overall satisfaction dial on the main game board (see figs. 2 and 3).

3. Satisfaction dials for each of the interest groups accessed by clicking on the overall satisfaction dial (fig. 4). The player can also view graphs of interest-group satisfaction over time.

4. Graphs of land and water-tract attributes over time (trends) (fig. 5).

5. Visual indication of island flooding.

6. Earthquake alerts with announcements of levee vulnerability if a weakness has been identified (for example, fig. 6).

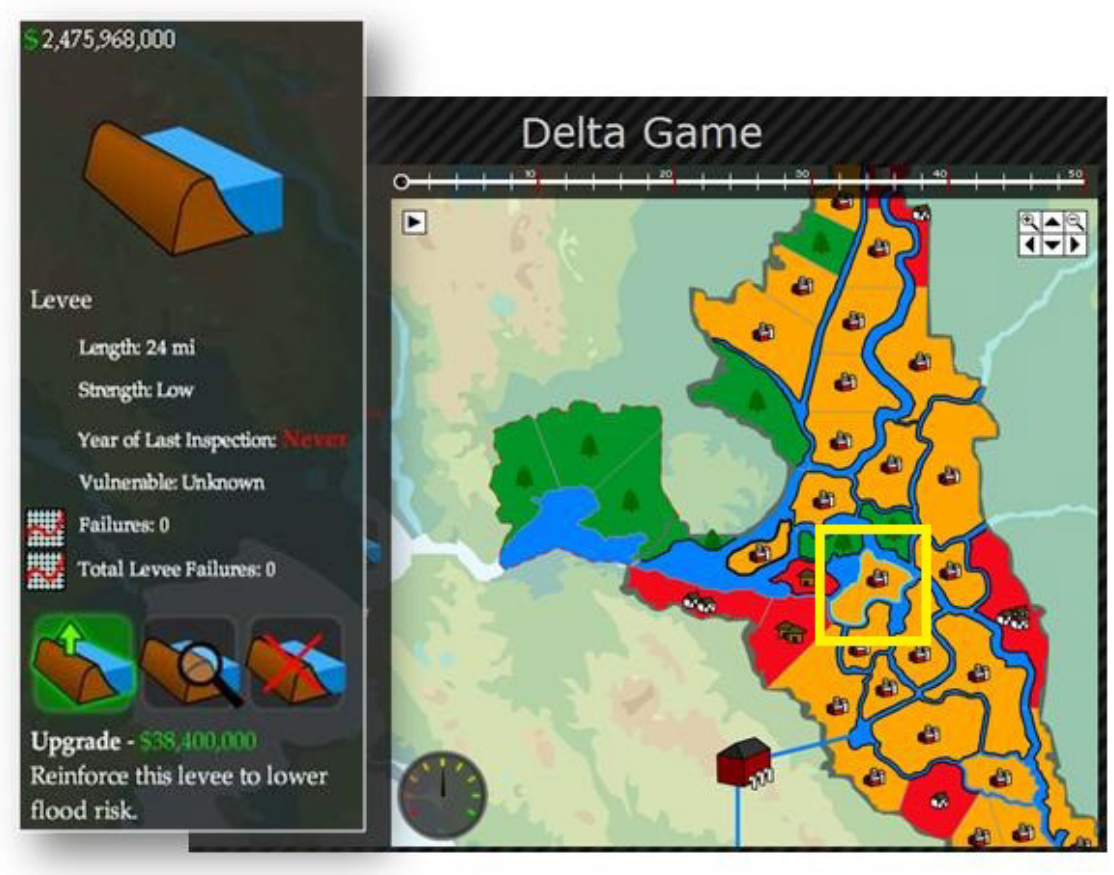

Figure 3. Delta Skelta game map with a levee highlighted by light blue outline (in yellow box). Left panel displays attributes of the levee condition. Player can select to inspect, upgrade, or remove the levee. 


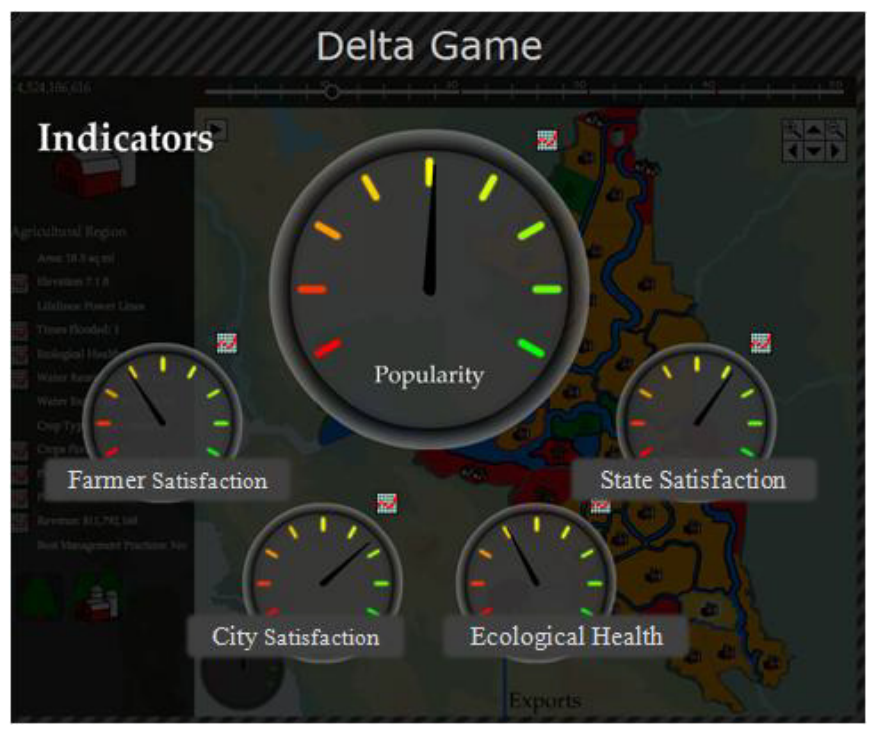

Figure 4. Delta Skelta players monitor the success based on the satisfaction of the four stakeholder groups.

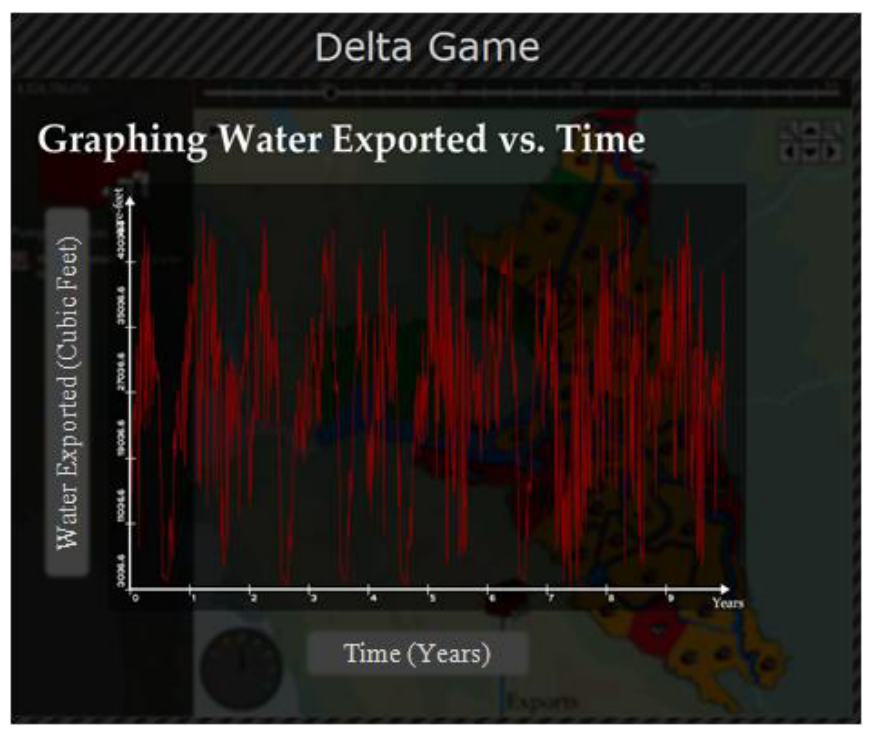

Figure 5. Graph of water exports over time presents an example of monitoring a Delta Skelta game variable over time. 


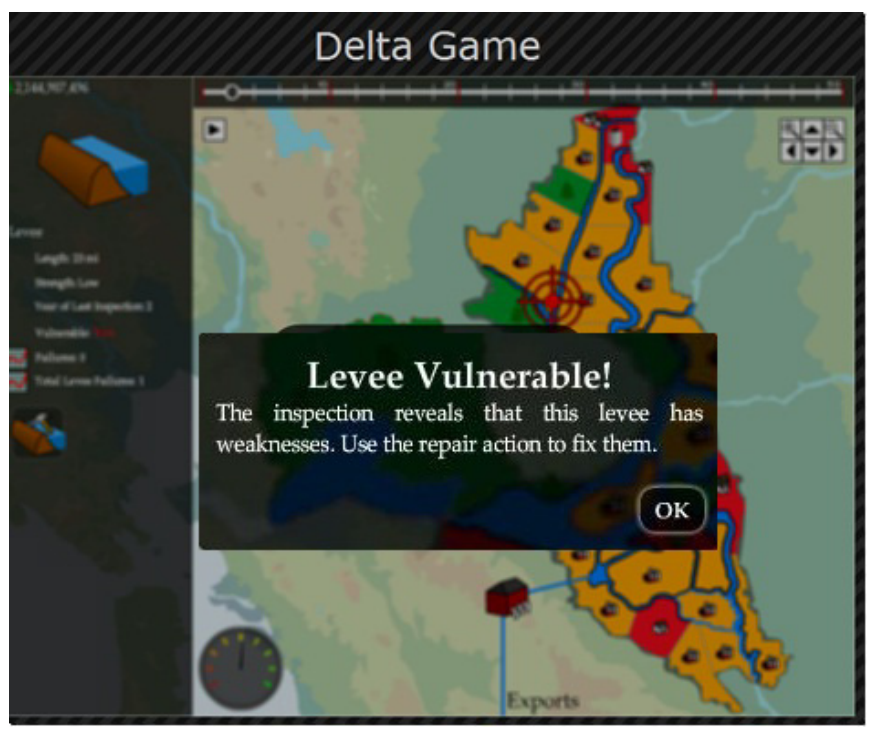

Figure 6. Following an earthquake (epicenter marked with red bull's eye), the Delta Skelta player may inspect levees and receive a levee-vulnerability alert.

The development of the game required subject and technical expertise and scientific data and models. Subject experts included hydrologists, ecologists, decision scientists, and an economist. One of the decision scientists had a background in water resources and environmental engineering. Technical expertise was provided by USGS scientists experienced with building simulations and optimization and reductionist models and by developers who had played and created computer games. USGS scientists constructed an influence diagram representation of the hydrologic and ecologic drivers, interactions between system components, and influences on interest group water-related goals to develop and communicate the game's management context with the game developers (fig. 1). The developers used Flash CS3 to run on Microsoft Windows as the game development platform.

Background information about delta issues and alternative futures are discussed by Lund and others (2007) and various online resources (for example, Delta Vision, 2008). Spatial data was excerpted from the Delta Atlas (California Department of Water Resources, 1995) to attribute land tracts with railroad, highway, and power-line infrastructure. A simplified water-resource model was based on an existing database and equations in Dayflow-a computer program developed in 1978 as an accounting tool for determining historical delta boundary hydrology (Interagency Ecological Program, 1978). With guidance from USGS water-resources scientists, the water-resource model was used to simulate varying sea levels and salinity. Land elevation was assumed to subside at a constant rate, but similarly aggrade when flooded.

Simple functions describe interest-group satisfaction as follows:

1. Farmer satisfaction is affected positively by revenue (dependent on water availability, water quality above a salinity threshold, and the external market) and a perception of protection from flooding. The more profitable water-intensive crops require larger water allocations.

2. Fish satisfaction is a function of habitat water quality (salinity cycles) and quantity. Relationships were based on the literature (Lucas and others, 2002; Monsen and others, 2007) and discussions with USGS experts (Lucas and Monsen, oral commun., June 12, 2007).

3. Cities thrive on abundant fresh (low salinity) water resources, population increases, and total population density, up to a point of congestion (forcing urban land-use designations to 
accommodate growth, while discouraging sprawl). City satisfaction is affected negatively by the proportion of the total population directly affected by floods or earthquakes, the proportion of essential infrastructures damaged by the hazards, and disaster memory (providing incentives for investments in hazard protection).

4. California State satisfaction is a function of water exports (relative to demand) and low salinity. Furthermore, the ecological health of natural lands has a positive effect on all of the interest-group satisfaction scores. The ecological health of natural tracts is enhanced when adjacent delta distributaries have high salinity (although the original intention was to reward natural regions when the salinity cycles mimicked more natural cycles), nearby farmers and cities use best-management practices, and adjacent lands are in a natural state. Conversely, ecological health of natural regions declines when water practices (such as the seawall barrier) allow only freshwater into nearby distributaries.

Delta Skelta was played internally, demonstrated to a group of scientists, and posted at the developers' game site. The following summer we built on the Delta Skelta experience to develop a second game.

\section{Age of Ecology}

Age of Ecology was motivated by the USGS science-strategy (United States Geological Survey, 2007) statement of need for integrated ecosystem science to address the ever-increasing emphasis on sustainable ecosystems and human systems. Age of Ecology was designed to facilitate exploration of some of the general principles of sustainable land and resource use in the presence of natural hazards. We wanted to capture the complexity and adaptive nature of ecologic and human systems interactions by using multi-agent modeling.

The purpose of Age of Ecology is to provide a game experience that:

1. Develops an appreciation of the complex multiscale spatial and temporal interactions between ecologic, geologic, and economic processes;

2. Teaches principles of sustainability within an evolving, complex human-ecological system, such that the player is rewarded for making use of natural resources in a long-term economically productive manner that does not discriminate against future generations; and

3. Exercises hazard-mitigation planning for multiple hazards.

Initially, another purpose of the game was to facilitate collaboration and compromise between multiple players through the collective establishment of rules and institutional solutions to achieve sustainable development, but the multi-player facility was not achievable in the time available for game development (five weeks).

The Age of Ecology game depicts a coastal landscape and challenges players to plan for sustainable development of that environment. The players purchase land, zone land use (natural, agricultural, cities, ports, levees, and fisheries), invest in the productive capacities of the land uses, and mitigate natural hazards (floods and earthquakes) to ensure sustainable development. City industries need the resources of population, infrastructure, and operating budgets, and they generate water and air pollution and revenues. Farm crops consume water and nutrients, while generating groundwater pollution to support the population's food demand and generate revenue. Fisheries provide a source of income that depends on the ecological health of the water bodies, fishing-net type, and the number of boats. The built environment and economic activity in the region are susceptible to flooding and earthquakes. Natural regions do not directly generate money, but they regenerate the environment 
through the provision of ecosystem services. The name of the game, Age of Ecology, was inspired by the environmentally nonsustainable aspects of the Age of Empires series (Ensemble Studios, 1997).

The main and ancillary target users are high school and undergraduate student audiences. The player's goal is to maximize long-term economic return from agriculture, fishing, and industry, in a world subject to natural hazards, without destroying the ecosystem services that make the system sustainable. A player is immortal, as long the ecological-economic system does not fail. The player, in the role of a regional planner, responds and adapts to political, economic, and environmental feedback from the system.

The player interface is a randomly generated coastal landscape that includes delineated coasts, inland water bodies, and terrain, such that each game board is unique. The terrain has a randomly generated topography, and each location is assigned a water cost applicable to crops grown on land zoned for agricultural use. (The water cost depends on distance to the nearest body of surface water). A paintbrush tool allows the player to delineate and buy tracts of land (fig. 7).

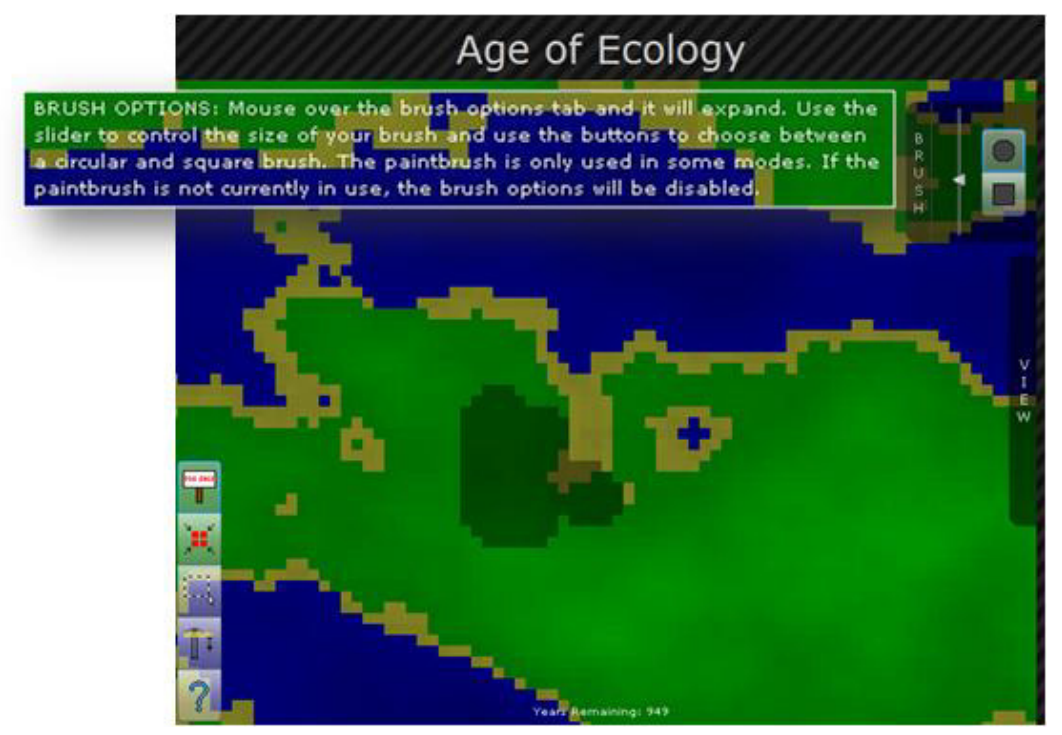

Figure 7. Each Age of Ecology game board is a randomly generated landscape and topography. Age of Ecology players use the paint brush tool to select land for purchase.

The computer software simulates farm, fishery, and industrial agents within the bounds of the player's decisions. An agent is an autonomous computer process that acts in its own interest and is capable of adapting to its environment. The agents provide a mechanism to encode scientific knowledge into the game. Agent-based models with multiple agents are particularly well-suited for representing complex spatial interactions under heterogeneous conditions and for modeling decentralized, autonomous decision making. Agents share an environment through agent communication and interaction; and they make decisions that tie behavior to the environment (Parker and others, 2003). For example, in Age of Ecology, every farm agent is an individual farmer with a heterogeneous willingness to take risks that uses water cost and nutrient data to decide which crop to grow every year. Industrial agents and fishing agents are also independent entities that are programmed to make simple, independent decisions. Industrial agents determine productivity by selecting from allowed industries and invoking population and infrastructure constraints. Fishery agents direct boats and nets toward the most densely populated fishing area adjacent to their current location to determine the fish catch. With agentbased modeling, the agents make profit-related decisions, leaving the sustainability decisions (like 
curbing pollution from cities even if it lowers profits in the short term) to the player. The computer software also simulates random failure of levees and flooding according to water level, topology, and levees. Earthquakes are generated probabilistically on the faultline that is mapped on the faultline layer.

A player's decisions include which land to buy (subject to a budget) and the designation of land uses for selected areas. On farmland parcels, the player chooses the crops to invest in, but can later disable any of the crop options available to farm agents. In the cities, the player chooses whether to invest in infrastructure and earthquake protection and enables/disables the industries available to industrial agents (fig. 8). For the fisheries, the player can invest in a number of boats and nets and manage the number of boats and types of nets sent out to fish (fig. 9). The player can implement flood protection by constructing levees along the coastline. Figure 10 presents a systems diagram of these components and the interaction between simulated agents and player decisions in Age of Ecology.

Player feedback is comprised of 22 thematic spatial layers of information available to monitor the state of the world. The thematic layers are Political (topography, ownership, zoning, population, infrastructure, and earthquake protection), Environmental (air pollution, water pollution, fisheries status, levees, flooding, fault lines, soil nitrogen, soil phosphorous, and soil potassium), and Economic (current profit, total profit, industry/crop type, fisheries, ports, levee cost, and water cost). For example, figures 11-13 illustrate the spatial extent of water pollution, condition of the fisheries, and total game profits. The player earns returns on investments in fishing, agriculture, and industry and loses money when the development is nonsustainable by negatively impacting ecological resilience. Players are alerted when floods and earthquakes occur and are notified of any levee breaches. The player's wealth suffers losses from the hazard events, but losses are reduced through investments in flood protection and earthquake mitigation. Ultimately, the player's mastery of sustainable development is reflected in the game score (profits).

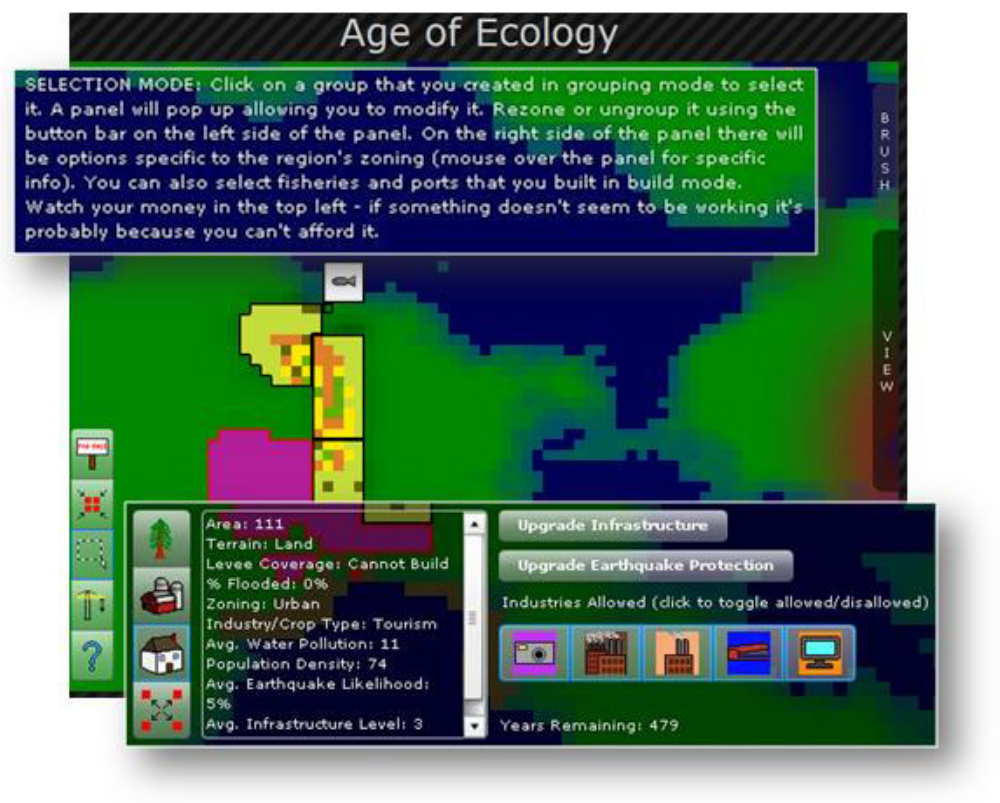

Figure 8. On city land, players enable industries (the pink area), upgrade infrastructure, and invest in earthquake protection. Similarly, on agricultural land, players invest in crops for rotation (the yellow, green, and orange pixels). This and the subsequent game board (fig. 9) shows a randomly generated landscape. 


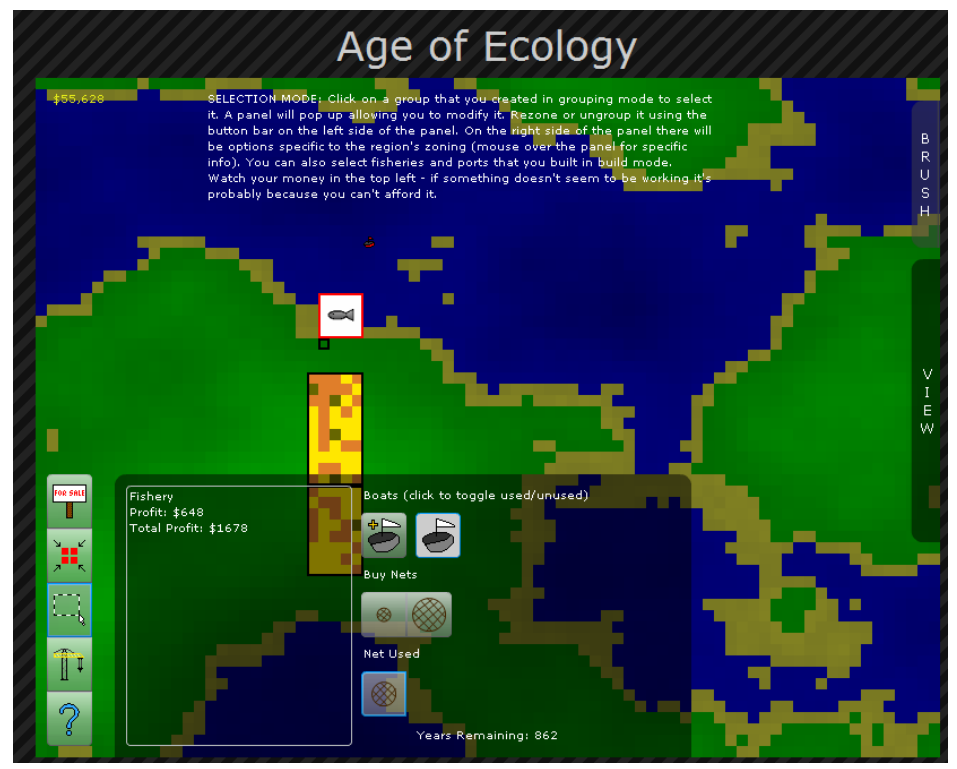

Figure 9. Age of Ecology players construct ports and invest in fishing boats and nets.

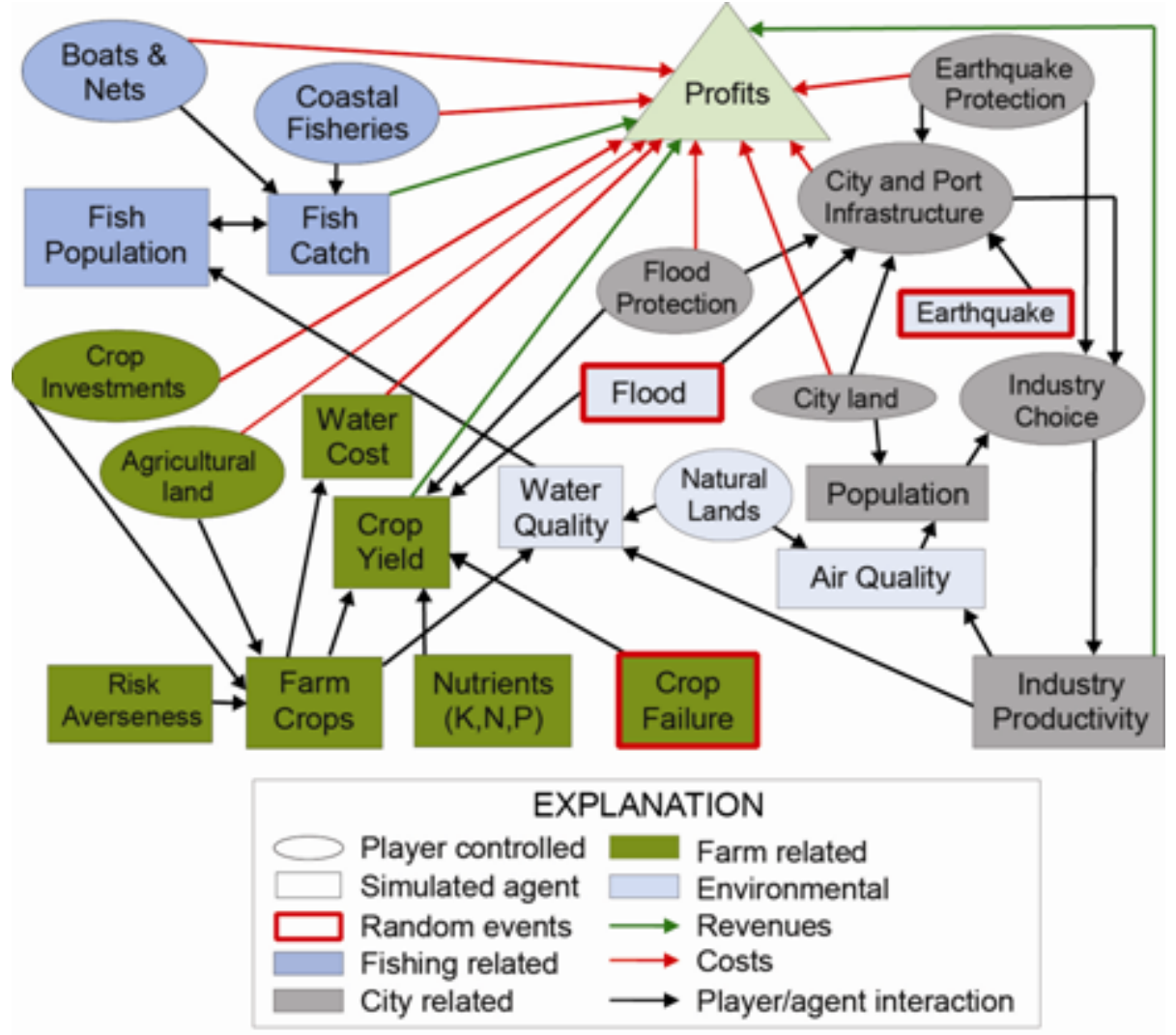

Figure 10. Diagram of Age of Ecology game. Fish, city, farm, and natural components contain player controlled decisions and autonomously simulated agents. Random simulated events of crop failure, flood, and earthquake occur that can be mitigated by farm crop, and hazard protection decisions. Player decisions and simulated agents interact, culminating in profits (represented by the green triangle) that measure player success. 


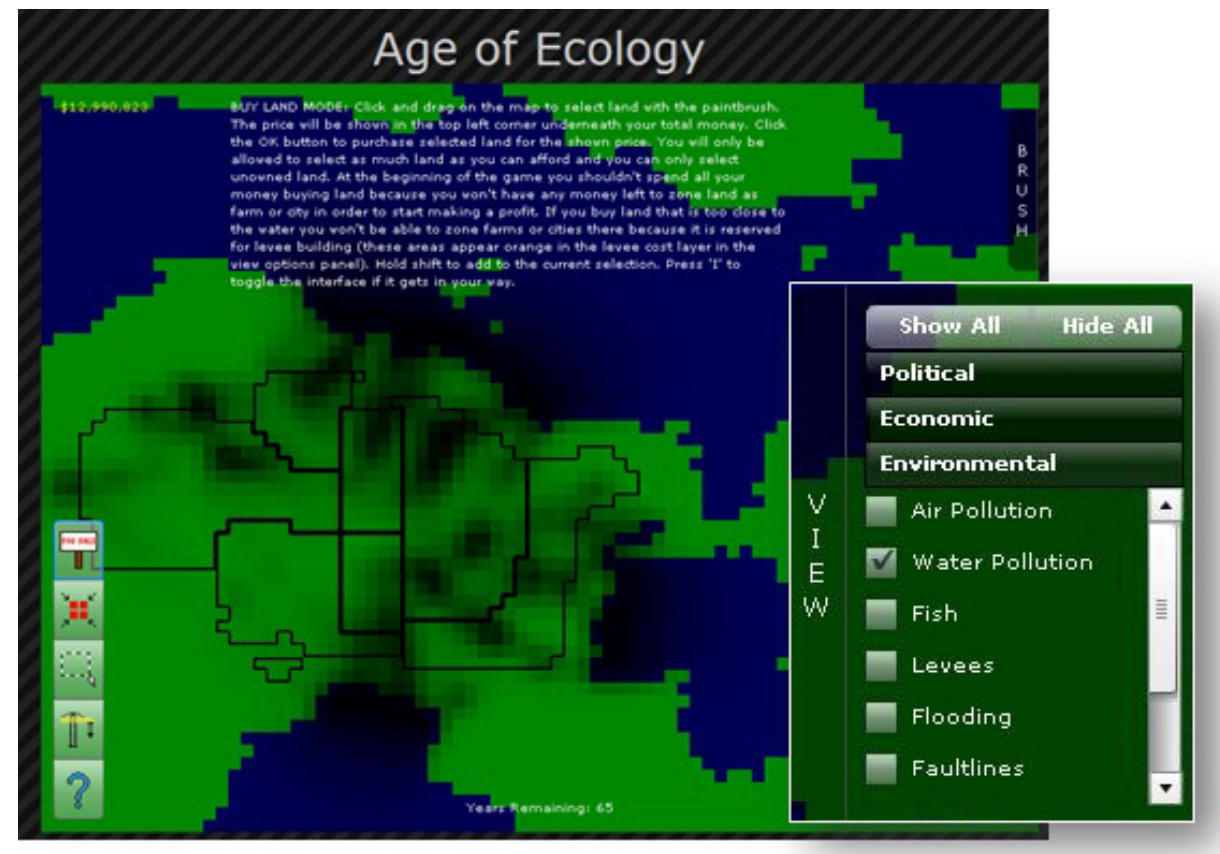

Figure 11. Players can monitor the environment in the Age of Ecology by displaying layers of information such as water pollution, indicated above in shades of gray.

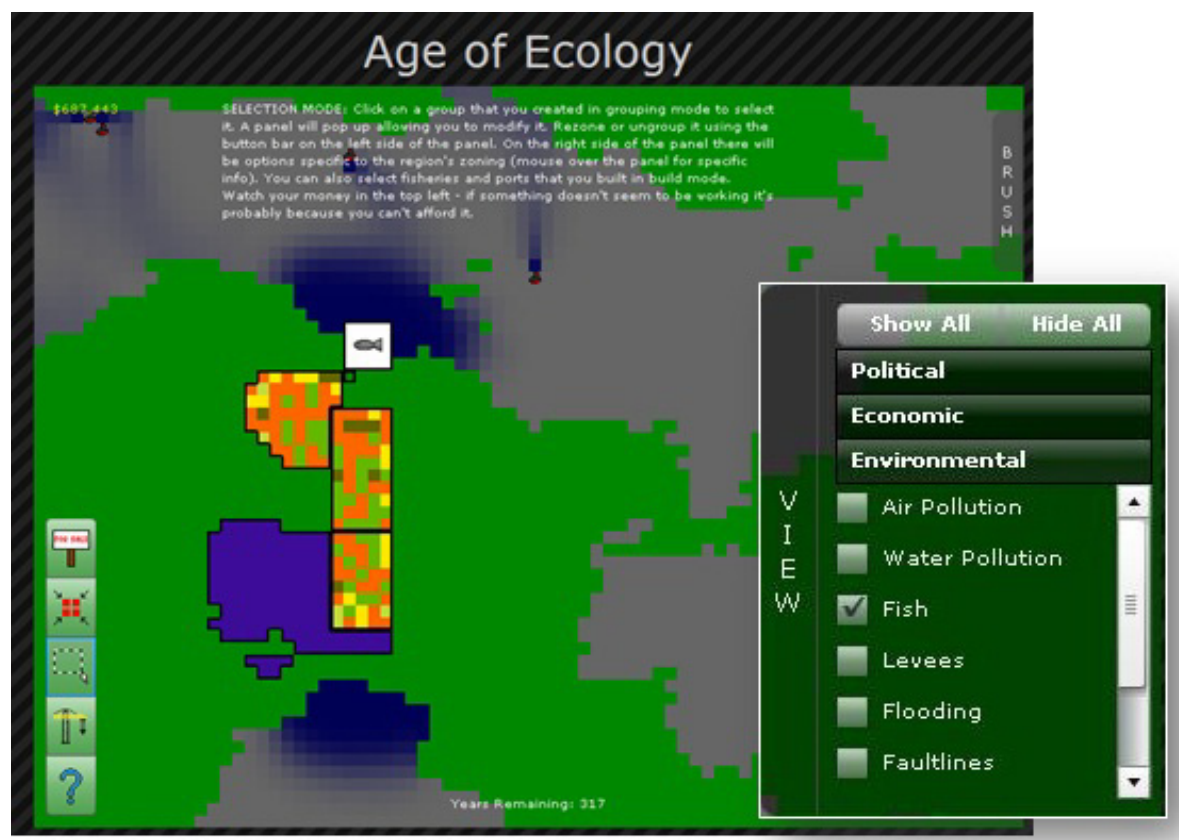

Figure 12. The player monitors the fish population in the Age of Ecology game. Depleted stocks are indicated by blue shading in the water bodies. The figure also displays agent-based crop rotations in orange, green, and yellow fields. The blue industrial area represents the professional-services sector. 


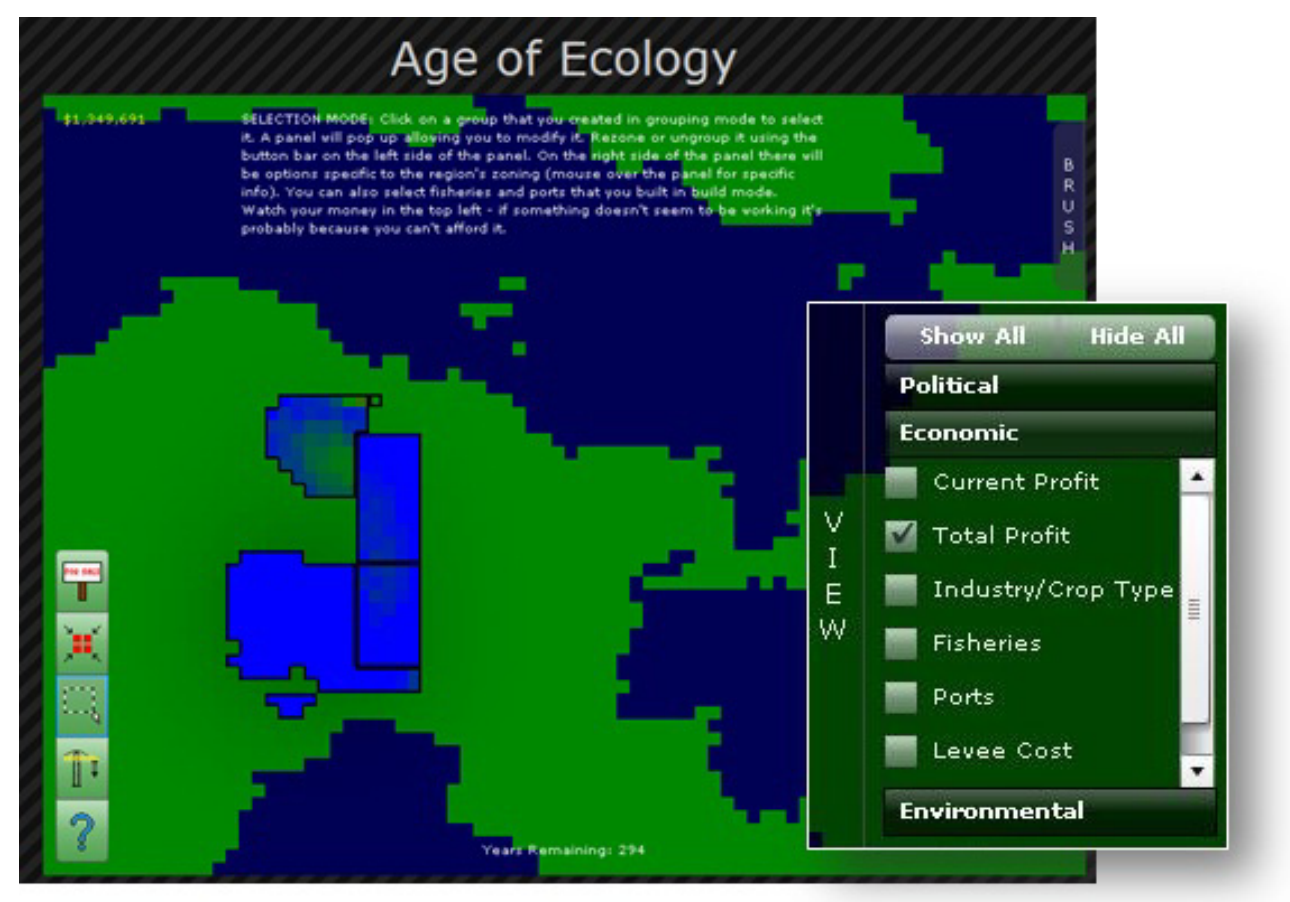

Figure 13. The Age of Ecology player can display the current distribution of game profits from agriculture and industry.

Technical expertise was provided by Professor Gary Pereira (San José State University) who introduced agent-based modeling to the developers by demonstrating Netlogo (Wilensky, 1998). The developers wrote Age of Ecology in Adobe ${ }^{\circledR}$ Flex $^{\mathrm{TM}}$ Builder 3 Pro for Education, a framework that uses ActionScript (Flash's programming language) and provides convenient HTML-style components. Free educational licenses are available at http://freeriatools.adobe.com. The program runs in a Microsoft Windows environment.

Subject expertise was provided by Bill Labiosa who moderated ecosystems management and ecosystem services and by Anne Wein who assisted with data sources and simple concepts of economic behavior.

Various resources were accessed for information to model agent decisions about city growth, farm-crop rotations, and fish catch, and to calculate the pollution from these activities.

- City growth dynamics were simplistically represented by the growth of a few industrial sectors that depend on population and infrastructure investments. Each industry has a minimum population needed to support it (for instance, high-tech requires a million people, while textiles requires a thousand), associated water and air pollution loadings, and a profitability. Each city pixel has a population and an industry (for example, ports and goods distribution, heavy manufacturing, hightechnology, tourism, and professional services). Population pixels are agents that update population based on population in previous time periods, population of surrounding pixels, and air quality. Relative air and water pollution from these industries was informed by United States Environmental Protection Agency (2002) and pollutants by industry were found at United States Environmental Protection Agency (2008). In general, it was difficult to associate water and air pollutants with industries because there are numerous water and air pollutants, and we encountered pollution calculators rather than a list of industrial sectors and generic levels of pollution. 
- Farms are much like cities with crop types substituting for industry type. Each crop type has water and nutrient consumption rates, produces water and air pollution, and generates profits per unit of production. Crop options and values, nutrient and water requirements, and pollution were based on Internet sources. Some crop values are reported in Delta Vision (2007). Some crop water requirements were based on work by Andales and others (2011) and Colorado State University, Cooperative Extension (2003).

- Fisheries provide a source of income that depends on the ecological health of the fishery, the type of fish net, and the number of boats sent out. Fishing-net attributes were inspired by a range of fishing nets (purse seine, bottom trawl, and mid-water trawl) and lines (pelagic long line and vertical hook and line). A link to information and data is available at the Pacific Fishery Management Council [n.d.]. Fishing areas are repopulated according to fish population and water-quality conditions, and fish migrations from one pixel to another.

The two serious games accomplish a first step towards using computer games and agent-based modeling to capture interactions, feedback, and adaptations within ecosystems. We critique the games later in this report, but first, we document some of the design decisions and trade-offs.

\section{Questions and Challenges}

Various game-design trade-offs arose during the development of the two serious games. Some of these trade-offs are not unique to our experience and are discussed in the literature. We identified and addressed eleven game elements during the design process, as follows:

\section{Fact versus Concept}

Instead of real-world accuracy, most games attempt to focus on providing just enough detail to simulate the feeling or key aspects of the system being modeled (Sawyer, 2002). Game designers may consciously introduce inaccuracies such that games sometimes convey misinformation or foster misconceptions. The compromise usually is made for entertainment purposes. For example, SimCity (Maxis, 1989) exaggerates the mayor's power and ignores issues of race (Squire and Jenkins, 2003). Hurricane Landfall amplifies building damages to create an emotional response (in line with what the real world response would be) and creates all roles as equal to level the power amongst players (Seth McGinnis, oral commun., August 14, 2008).

The accuracy issue is, perhaps, more of a challenge for an organization, such as the USGS that strives to provide objective and scientifically rigorous information. The USGS belongs to the community that is "rooted in the scientific method and principles to strive for complete understanding of a subject, prove a specific theory, or create an accurate prediction of existing systems" (Sawyer, 2002). However, it is apparent that gamers have the technology to improve the accuracy of games (especially models based on empirical methods), and serious games provide an opportunity to learn how decisionmakers interact with scientific information.

The guidance from the literature is to make the game correct to the point that it teaches the right skills; therefore, it is essential to understand the link between game purpose and accuracy. Our two games had different purposes. Delta Skelta emulates a real place and real decisions, and Age of Ecology more abstractly teaches concepts of sustainability. We think scientific integrity is more critical in a Delta Skelta-type game, and that we had more leeway to be conceptually accurate in the Age of Ecology. In the case of Delta Skelta, the need for more accurate representation of scientific information suggests a large interdisciplinary state-of-the-art modeling and simulation effort might be needed. 


\section{Teaching Facts versus Developing Strategic Thinking}

We wanted to avoid producing games that were glamorized flash cards or quizzes that focus on teaching facts. Game researchers see the value of games as a means to develop investigative skills and strategic thinking. We concur, but also hypothesize that game playing can encourage fact finding by providing links to research and resources from the game interface. Although Delta Skelta commentary connects players to some relevant fact sheets, neither game motivates players to link to online resources.

\section{Winning the Game: Wealth versus Satisfaction}

The bottom line in our games, and often in practice, is money, but financial gains fall short of measuring other societal values. Delta Skelta players were constrained by budgets, but four stakeholdersatisfaction ratings determined their success. Age of Ecology was controlled only by money, and unsustainable actions eventually affected the income stream. Another measurement of success compares game outcomes with player declared values. For example, SimHealth took this approach by prompting players to declare their values (balancing Liberty against Quality and Community against Efficiency), to create new policies and to change existing ones, and then to evaluate the compatibility of their policy decisions and personal values.

\section{Serious versus Fun}

We read of two opposing views on the fun factor. Some believe that the entertainment component comes before pedagogy (Michael and Chen, 2006). Others are bothered by the "obsession of turning the classroom into a funhouse” that degrades scholarship, dulls questioning minds, and substitutes quick answers and fast action for reflection and thinking (Stoll, 1999). A compromise seems to be to get players to learn something and, if possible, have fun (Michael and Chen, 2006). We concluded that a game might be "fun" or not, but it has to be engaging: The key is to stimulate intense and passionate involvement with goals that motivate and rules that provide structure (Prensky, 2001). We note that complex games were ranked highly by MIT students who were surveyed about their favorite game titles (Squire and Jenkins, 2006).

We asked the developers to list the elements of a fun game. Their responses included:

- A good and captivating story with interesting characters.

- Plenty of player control, opportunities to make decisions in real-time, and capability for players to design/build their own scenes. A boring game prompts users to make a decision and to click on a multiple choice answer.

- A progressive challenge as a player succeeds at each level of play. Puzzles are fun the first time round, but not to play over and over, so they need to change, as well.

- Good graphics and animation.

- Good music and sound effects.

- Movie introductions and transitions between levels.

- Humor.

A similar survey in Saunders and Severn (1999) adds a preference for simple instructions to get started fast (without having to read an instruction manual).

The interns were not able to incorporate all of the fun elements into the games in the time available, but they did inject some humor into the Delta Skelta newspaper articles, and they learned 
from one game to the next. One of the fun-factor differences between Delta Skelta and Age of Ecology is player control. The developers noted that one problem they saw with Delta Skelta's fun factor was that the player did little much of the time-mostly acting when earthquakes hit. In order to keep Age of Ecology fun, the interns aimed to have the user in control of many important decisions that allow them to actively shape their environment. Retaining player control, therefore, is an important consideration in game design. Although a more action-packed game appeals to the game-playing crowd, a speed slider on Age of Ecology can be set on slow by players who want the time to investigate the game board and monitor the results of their decisions by using the thematic layers, thereby, addressing Stoll's concern about the need to facilitate reflective thinking.

\section{Games for the Uninitiated Player versus the Gamer}

We realized that gaming is a culture of strategic thinking and physical and mental dexterity in response to simulated situations. The speed of play can be overwhelming to an uninitiated player; therefore, our games include the built-in option to allow the player to control the time spent making major decisions (Delta Skelta), or to slow the play (Age of Ecology). In addition, Age of Ecology players can choose the level of game difficulty by setting levels of environmental resilience and the likelihood of natural disasters (fig. 14).

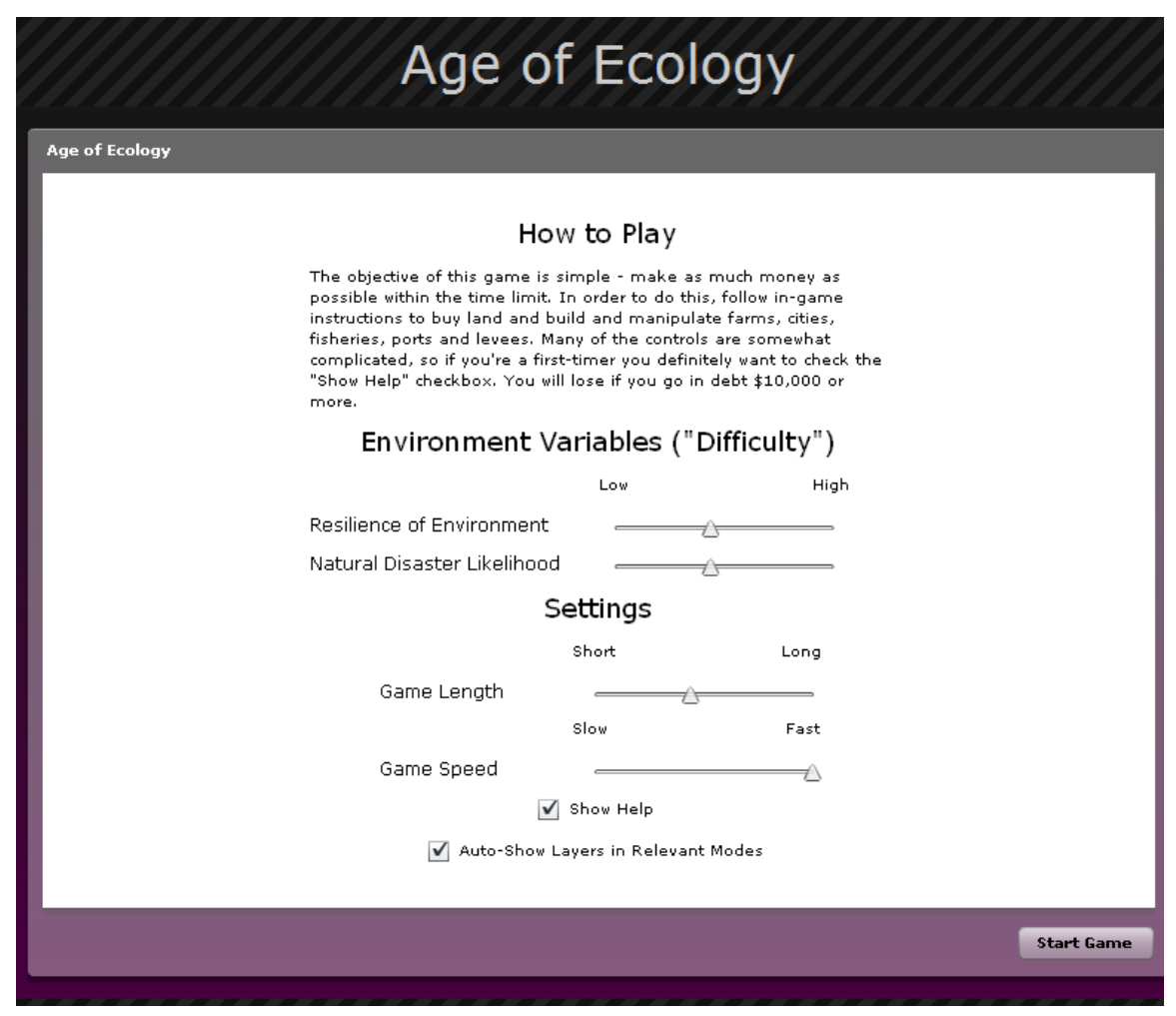

Figure 14. Prior to playing the game, Age of Ecology players adjust the difficulty, length, and speed of the game. More difficult games have a lower environmental resilience and (or) more frequent occurrences of natural disasters. 


\section{Student Players versus Policymaker Players}

Another player distinction is students versus practitioners or decisionmakers. We had the latter in mind when we embarked on Delta Skelta. We wondered if serious games can provide a forum to explore and discuss complex policy decisions. In contrast, Age of Ecology was aimed at teaching sustainability concepts to students. The intended user does affect the game design. We conjecture that games for stakeholders could involve them in one of three ways (Parker and others, 2003): (1) stakeholders participate in all stages of the game design and development, (2) stakeholders participate in the game play and interact with game agents, and (or) (3) the game is presented to policymakers as a fully functioning scenario-analysis tool in order to test policy alternatives. Stakeholder involvement in the game design and play declines from one option to the next, but more stakeholder involvement may result in a less imaginative and engaging game (Seth McGinnis, oral commun., August 2008).

\section{Single versus Multi-player}

Another consideration is the number of players to accommodate. Multi-player games provide the additional capacity for players to compete against and cooperate with each other and to partake in collective decision-making that is appropriate for policy games. Delta Skelta is a single-player game, but demonstration of the game to a group of scientists stimulated conversation about policy issues and the scientific underpinnings of the game. We intended Age of Ecology to be a multi-player game, but this feature was not achievable within 5 weeks of design and development. However, we observed single players becoming absorbed by the Age of Ecology. ${ }^{1}$

\section{Player Action versus Rules for Agents}

As noted above there are some game interactions and responses that can be left to the player, or automated by using agent-based models. There are three levels of interactions to consider: (1) individual player and agent decisions in response to environmental variables, (2) communication and coordination between decision makers or agents, and (3) mediating decision makers or agents (Bousquet and others, 1999). Delta Skelta is simulation-based, but Age of Ecology embraced agents to increase interaction and realism. The latter was implemented to relieve the player of repetitive decisions, such as having to choose annual crop rotations and places to fish. Over time, the rules for agents can encapsulate new scientific understanding.

\section{Short-term versus Long-term Decisionmaking}

We attempted to address decisions with short-term pressures, but long-term time horizons. In fact, the governor's plan for Delta Vision was to consider 50-, 100-, and 200-year planning horizons (Delta Vision, 2011). Delta Skelta rewards long-term decision making (for example, investments in levee maintenance) and challenges the player to survive the length of the game without being kicked out of office. Age of Ecology players reap the economic benefits of agricultural, fishing, and industrial activities, but air and water pollution accumulates over time and eventually affects the productivity of the region if the player does not keep pollution in check.

\footnotetext{
${ }^{1}$ We observed Age of Ecology being played at the Interservice/Industry Training, Simulation and Education Conference (I/ITESEC) in Orlando, Fla., Dec. 1-4, 2008, where the game won the student category of the 2008 Serious Game Showcase and Challenge.
} 


\section{Stochastic versus Deterministic: Luck versus Skill}

There are many inherent uncertainties in complex natural and human systems that are only exacerbated by longer time horizons. At the outset of our serious-game experiment, we assumed a potential to use serious games to create an experience of decision-making under uncertainty. We hypothesized that a game environment would allow players to explore particular realizations of scenarios through repeatedly playing the game. Thus, we hypothesized that players could learn about: (1) uncertain trade-offs between objectives under a variety of circumstances; (2) the importance of various demographic, natural-hazard, and climate contingencies; (3) the importance of technological change; and (4) the role of scientific and other information in planning. However, this thinking is somewhat adverse to game play for two reasons: (1) repeat game players tend to look for the next level of play, rather than wanting to not repeat the same level; and (2) game players want to conquer the game by using skill, not luck. There are no levels in Delta Skelta, but Age of Ecology players can challenge themselves by adjusting game-speed or difficulty sliders (fig. 14). The developers reacted to the "too much luck" component of Delta Skelta by incorporating fewer probabilistic elements in Age of Ecology, such that if players use the same strategy more than once, they will get very similar results both each time. Although games need to respond to conscious decisions rather than chance, imperfect communication of information is not an unreasonable assumption about the real world (Michael and Chen, 2006). The level of stochasticity is related to the one final trade-off that follows.

\section{Learning from Single Play versus Multiple Plays}

We understand that most training games aim to teach the player during a single play of the game. However, one can imagine that players could learn from their play by analyzing data gathered automatically during play. We had envisioned this functionality for Delta Skelta, but it was not built into the game during the time we had available. Players could also learn from multiple plays by taking on different roles with different objectives.

\section{Critique of Serious Game Experiments}

We played and critiqued the two games and asked the following questions: (1) Do the games satisfy game principles? (2) How could the game design be improved? (3) How could the scientific and other types of content be improved? (4) What are the novel features of the games?

\section{Satisfaction of Game Principles}

We compiled a list of serious-game criteria from Sawyer (2002) and the 2008 Serious Game Showcase and Challenge (DiSTI, 2008) as follows:

1. Assigns a challenge by setting goals and sub-goals;

2. Requires players to affect the outcome of the game;

3. Provides appropriate feedback (positive and negative) to players;

4. Requires mental or physical skill;

5. Has an outcome uncertain at the outset;

6. Requires players to develop and discover strategies to win;

7. Is designed for players to overcome most obstacles (that is, the game is winnable); and

8. Is interesting and fun in order to inspire repeated play. 
Although both games satisfy these game criteria, we thought about improving player feedback and experience.

\section{Improving Player Feedback and Experience}

Regarding player feedback, we appreciate the advice to "design to fail, but motivate to learn (give hints)” (Seth McGinnis, oral commun., 2008). For example, players will lose interest playing Delta Skelta if they cannot understand why their farmer and ecological ratings are going down and what to do about it. Players will be discouraged to replay if there is nothing they can do to prevent a natural hazard (earthquake) from ending the game. These concerns underscore the importance of the interplay between the encoded scientific information and the players' actions. Although Age of Ecology provides some hints up front, and 22 layers of information to monitor the state of the environment, the player could be made more aware of problems by implementing SimCity-type complainers. For example, the game could issue complaints about low fish catch (fishermen), no jobs (cities), air pollution (cities), infrastructure (industries), water costs (farmers), and environmental violations (regulators). We also recommend more feedback at the end of Age of Ecology. Rather than simply announcing how much money the player made, a sustainability report or rating about the state of the world, trends, and its future would be more insightful.

Player experience is currently limited by player options and to input from a single player only. Examples of incomplete options include:

1. Delta Skelta does not offer the option of building a bypass channel from the upper Sacramento directly to the delta's mouth to the keep the delta fresh. The player has no control over water management through dam releases, maximum reservoir levels, and minimum downstream flows.

2. Age of Ecology does not offer investments into technological solutions to reduce pollution levels.

Neither Delta Skelta nor Age of Ecology support a multi-player feature, and therefore, do not provide a forum for players to be affected by other player's actions, to compete, to cooperate, or to collaborate on establishing rules and making collective choices. A multi-player feature could be incorporated without altering existing architecture.

\section{Representation of Complex Geological, Ecological, and Economic Systems}

Our games are incomplete representations of the ecosystems, run on simplified scientific processes and interactions among them, and they introduce some misconceptions. Examples of incomplete representation of systems in each game include:

1. Delta Skelta ignores water storage and dams for use as environmental flows, agricultural water, and public water supply. Fish spawning conditions also are not affected by player actions (for example, levee building and development).

2. Age of Ecology, purported as a sustainability game, does not account for energy resources and use. In reality, natural land uses also generate income through recreation and tourism. Although these natural land uses positively affect all the satisfaction scores of interest groups, these relationships could be improved by detailing and monitoring ecosystem services and incorporating valuation methodology.

Scientific, social, and economic processes are simplified in the following ways:

1. Delta Skelta models of sea-level rise, population growth, and city and farm productivity are highly simplified and, in some cases, intuitive rather than developed by using scientific rigor. 
2. Age of Ecology, at best, invokes effects of crops and industries on water and air pollution that are relative to each other. City growth and development is rudimentary. Agricultural economics and urban simulation could be tapped to increase the sophistication of the agent-based modeling.

A misconception in the Age of Ecology is an exaggeration of the role of levees, outside of delta regions, to protect coastlines. The notion of sustainability and making as much money as possible could be counter-intuitive. There is no groundwater, and only agricultural land uses are charged for water use and the price depends on distance to surface water.

As discussed in the "Fact versus Concept" section, a serious game needs to capture the most essential and important aspects of the problem, as accurately as is feasible and reasonable.

\section{Novel Game Features}

The developers incorporated some novel features into the Age of Ecology:

1. They named Age of Ecology after a popular, but environmentally unsustainable game, Age of Empires, to contrast strategies that support human civilization for future years with actions of hoarding and consuming resources.

2. A paint brush tool interface is a fun and easy way to select land for purchase and for land-use zoning without restricting the player to predefined spatial units.

3. The 22 spatial layers of information offer a unique ability to monitor the landscape and to investigate the outcomes of decisions.

4. The use of agent-based modeling enables interactions among entities without always involving the player. For example, agent-based modeling simulates profit-maximizing decisions according to agent attributes and environmental states.

\section{Discussion and Future Directions}

This project has begun an exploration of the potential for scientifically based serious games and provides useful examples of their use in various resource-management situations. We have produced two serious games about resource-management problems that promote integrated understanding of scientific information, one location-specific and the other based on a generic landscape. We have identified a number of computer game design questions, including fact versus concept and serious versus fun. The two serious game experiments satisfy game principles. We focused on demonstrations of concepts, rather than on managing an extensive serious game development process of defining and creating a game to bring to market. Thus, the goal was not to develop games that would become widely used, which would require extensive focus-testing and other market-based approaches, but rather to demonstrate, within the USGS, the potential for such games to make acceptable use of scientific information within challenging resource-management contexts. The purpose of this study was to explore the potential for serious games to increase the impact and audience for USGS-generated scientific information.

Initially, we hypothesized that serious games provide an alternative and progressive medium for (1) communicating USGS scientific information, (2) teaching scientific concepts, (3) experiencing and developing understanding of societal trade-offs, and ultimately, (4) informing decisionmaking under uncertainty. Currently, the main outlets for science-based serious games may be university classes and science teacher association meetings (Seth McGinnis, oral commun., August 14, 2008). In terms of educational objectives, the Federal Emergency Management Agency (FEMA) has taken a step in this direction by providing simple games for kids at their educational Web site (Federal Emergency 
Management Agency, 2013). The National Oceanic and Atmospheric Administration's (NOAA) compendium of games includes a serious game (National Oceanic and Atmospheric Administration, 2011). The USGS currently provides scientific information "to help educate the public about natural resources, natural hazards, geospatial data, and issues that affect our quality of life” (United States Geological Survey, 2008). Serious games involving hazard processes, ecosystem-based management, resource management, and sustainability could be added to the slate of online USGS resources for education (K-12) and university-level inquiry and research.

We understand that serious games are not a substitute for all traditional learning practices, however, they can be linked to real-world experiences and to textbook knowledge to create a richer learning environment. The learning gains have less to do with increases in factual recall or the ability to choose correct answers and more to do with making complex ideas accessible to a different kind of student (Squire and Jenkins, 2003). Delta Skelta and Age of Ecology illustrate the potential for serious games to provide a more interactive way of learning about the complexity of ecosystems and ecosystem change, rather than a more passive and linear textbook presentation of the material. In these two games, individual players must follow their own lines of inquiry and actively investigate the state of the world to make effective decisions. Scholastic games must align with classroom objectives and be accepted as an effective and efficient way to teach material to satisfy academic-performance measures. Squire and Jenkins (2003) advise that moving educational gaming to the next level will require hard work and a real commitment of resources. They believe the best results will come through collaboration between educators and game designers. Educators acting alone are unlikely to fully grasp what makes contemporary commercial games so compelling for their players; game designers acting alone may not fully grasp the challenges of designing problems and activities that will fully achieve pedagogical objectives. The games that emerge cannot be seen cynically as rewards for learning. Rather, they need to be considered from the outset as organic to the educational process. More research is called for to understand the conditions for engaging and effective game playing to inform improvements (National Research Council, 2011).

The above third and fourth points hypothesized experiential learning and decision-support roles for serious games are more ambitious. Ultimately, we envisioned games played by stakeholders in a public meeting setting with players learning about the complexities involved and the existence of various information sources, developing integrated understanding, exploring resource-management policies for a variety of scenarios, and discussing tabulated results and insights gained by the group. In support of this vision, Tsuchiya and Tsuchiya (1999) report that games facilitate the creation of a new shared mental model among participants as an essential part of the process of social learning that precedes any collective decision making (Pahl-Wostl and Hare, 2004). Reportedly, policy games such as SimHealth and Corridor, at the Federal and regional level, enhanced policy discussions of the time. Furthermore, Hurricane Landfall has demonstrated a game design for groups of players to practice collectively establishing policy and rules. We witnessed how a demonstration of Delta Skelta facilitated a group discussion among physical and social scientists regarding the features of the game and uses of scientific information. Further investigations are needed to understand what games can and cannot do well and to avoid overselling the technology for creating experiences and supporting decisionmaking.

It will take an interdisciplinary USGS team and collaborations to build a serious game for any of these purposes. There are a couple of possible approaches: extending USGS models, simulations, scenarios, and decision-support systems into a game format, or piggy backing on existing game successes (for example, games for urban planners) by adding new and (or) improved scientific elements (ecosystems, climate change, and natural hazards) to expand, improve, and enrich these games. Either way, USGS collaboration with serious-game developers would expand our own scientific modeling 
capabilities toward agent-based modeling of ecosystem-based management. Parker and others (2003) find that multi-agent simulations are well-suited to modeling interactions and feedbacks between socioeconomic and biophysical environments and representing socioeconomic and biophysical complexity that is difficult to model in a purely analytical or statistical framework. They note that within the field of natural-resource management there is substantial interest in using multi-agent simulation models to understand common-pool resource problems and how institutional rules may direct individuals to act in the benefit of the collective. With game developers on board, a polished and professional looking game is assured (Seth McGinnis, oral commun., August 14, 2008). The game developers quickly programmed our games, but the scientific and technical work required to create the games to be done involved assessment of stakeholder needs, game design, acquiring models and data to meet the objectives of the game, and evaluation of the effectiveness of games while addressing some of the game-design questions raised in the "Questions and Challenges" section. The delivery of the product involves further commitments to software engineering and lifecycle management, including public/open-source release, platform independence, rigorous testing, update and technical support, documentation, and teaching aids. By working with students, we avoided some of the differences between commercial enterprise and the public domain that can complicate collaborations. These differences pertain to cultures, cost and profit, development timeframes and structure, intellectual property rights, and interaction and sharing between communities (Sawyer, 2002).

In conclusion, as the USGS positions itself to communicate and convey the results of multiple science-strategy missions, including natural-resource security and sustainability, serious-game development and agent-based modeling offer a means to (1) establish interdisciplinary and collaborative teams with a focused integrated outcome; (2) contribute to the modeling of interaction, feedback, and adaptation of ecosystems; and (3) enable social learning through a state-of-the-art medium. First, serious-game development for a complex resource-management problem demands collaborative scientific research and out-of-the-box thinking. The timing of this investigation aligns with recent strategic science planning that emphasizes cross-mission area synergies, including the integration of scientific datasets and models to improve integrated understanding of complex problems and inform decisionmaking. Second, expansion of scientific understanding onto a gaming platform promises enhancement of our modeling capabilities (for example, agent-based modeling), computer interfaces, and representation of complex systems with interacting and interdependent parts. Games can represent ecosystem interactions, feedback, and adaptation and make them visible and interactive for the player (National Research Council, 2004). Third, serious games make science accessible and facilitate social learning and the creation of shared mental models for societal decisionmaking. We believe it is important to consider serious games as a strategy to educate a generation that is increasingly more technologically astute and to reach groups that might not otherwise participate in science.

\section{Acknowledgments}

The two students, Carl Jackson and Alexander Wein, enabled our foray into serious games by willingly working with us to program the two games during two consecutive summers. Leonard Gaydos and Richard Bernknopf supported the initiation of this project and participated in some of Delta Skelta game-design meetings. Gary Pereira, San José State University, welcomed us at his geography lab to explain and demonstrate agent-based modeling. Jie Wang hosted the students at Stanford University during the development of Age of Ecology. Jeff Peters and Jamie Ratliff patiently assisted with the figures, references, and formatting of this report. Finally, Sky Bristol and Richard Taketa provided insightful comments on this report. 


\section{References Cited}

Abt, C., 1970, Serious Games: New York, Viking Press, 176pp.

Andales, A.A., Chavez, J.L., and Bauder, T.A., 2011, Irrigation scheduling-The water balance approach: Colorado State University Extension Fact Sheet no. 4.707

[http://www.ext.colostate.edu/pubs/Crops/04707.html, last accessed June 24, 2013].

Bousquet, F., Barreteau, O., Le Page, C., Mullon, C., and Weber, J., 1999, An environmental modeling approach-The use of multi-agent simulations, in Blasco, F., ed., Advance in environmental and ecological modeling: Elsevier, Paris, p. 113-122.

California Department of Water Resources, 1995, Delta Atlas:

[http://baydeltaoffice.water.ca.gov/DeltaAtlas/, last accessed June 20, 2013].

Colorado State University, Cooperative Extension, 2003, Crop production with limited water, from the ground up: Agronomy News, April 2003, v. 23, no.2, [http://www.extsoilcrop.colostate.edu/Newsletters/documents/2003_drought.pdf, last accessed June 24, 2013].

Delta Vision, 2007, Context memorandum: Agriculture in the Delta, Iteration 2, August 10, 2007, [http://deltavision.ca.gov/Context_memos/Agriculture/Agriculture_Iteration2.pdf, last accessed June 24, 2013].

Delta Vision, 2008, Our vision for the California delta: Governor’s Delta Vision Blue Ribbon Task Force, [http://deltavision.ca.gov/BlueRibbonTaskForce/FinalVision/Delta_Vision_Final.pdf, last accessed June 17, 2013].

Delta Vision, 2011, Delta Vision Foundation | Home: Delta Vision Foundation, [http://www.deltavisionfoundation.org/index.php, last accessed June 20, 2013].

DiSTI, 2008, Serious Games Showcase \& Challenge: I/ITSEC, National Training and Simulation Association, [http://www.disti.com/SGSC/index.html, last accessed June 20, 2013].

Ensemble Studios, 1997, Age of Empires: Microsoft Studios.

Federal Emergency Management Agency, 2013, Fun \& Games | Ready.gov: United States Department of Homeland Security [http://www.ready.gov/kids/fun-games, last accessed June 20, 2103].

Firaxis Games, 2001, Sid Meier’s Civilization III: Infogrames.

Fridirici, R., 2007, Floods of People-Migration and Opportunity Versus Flood Risk in San Joaquin County, California: in Flood Hazards in the Central Valley, Annual Meeting of the Association of American Geographers, San Francisco, April 21, 2007.

Gee, J. P., and Shaffer, D.W., 2010, Looking where the light is bad-Video games and the future of assessment: Phi Delta Kappa International Edge, v. 6, no.1, 27pp. 
Hatfield, D., 2011, The right kind of telling-An analysis of feedback and learning in a journalism epistemic game: University of Wisconsin-Madison, 127pp, [http://edgaps.org/gaps/, last accessed June 17, 2013].

Ingebritsen, S.E., Ikehara, M.E., Galloway, D.L., and Jones, D.R., 2000, Delta subsidence in California-The sinking heart of the state: U.S. Geological Survey Fact Sheet 005-00, [http://ca.water.usgs.gov/archive/reports/fs00500/fs00500.pdf, last accessed May 5, 2013].

Interagency Ecological Program, 1978, Dayflow: California Department of Water Resources, [http://www.water.ca.gov/dayflow/, last accessed June 17, 2013].

Lucas, L.V. Cloern, J.E., Thompson, J.K., and Monsen, N.E., 2002, Functional variability of habitats within the Sacramento-San Joaquin Delta-Restoration implications: Ecological Applications, v. 12, no. 5, p. 1,528-1,547, [http://www.jstor.org/stable/3099989, last accessed June 24, 2013].

Lund, J., Hanak, E., Fleenor, W., Howitt, R., Mount, J., and Moyle, P., 2007, Envisioning futures for the Sacramento-San Joaquin Delta: Public Policy Institute of California, 324 p.

Massachusetts Institute of Technology [n.d.], Environmental Detectives:

[http://education.mit.edu/ar/ed.html, last accessed June 18, 2013].

Maxis, 1989, SimCity: Maxis, Brøderbund Software Inc.

Maxis, 1994, SimHealth: The National Health Care Simulation, Thinking Tools, Inc.

Michael, D., and Chen, S., 2006, Serious games, games that educate, train, and inform: Boston, Mass.: Thomson Course Technology, 312pp.

Monsen, N.E., Cloern, J.E., Burau, J.R., 2007, Effects of flow diversions on water and habitat qualityExamples from California's highly manipulated Sacramento-San Joaquin Delta: San Francisco Estuary and Watershed Science, v. 5, no. 3, [http://escholarship.org/uc/item/04822861, last accessed June 17, 2013], 16pp.

National Center for Atmospheric Research (NCAR), University Corporation for Atmospheric Research (UCAR), 2006, Disaster Dynamics-Hurricane Landfall: [http://www.dd.ucar.edu/home.html, last accessed June 18, 2013].

National Fire Academy, United States Forest Service, [n.d.], 3D Wild Land Fire Fighting Training Simulator: United States Department of Agriculture, Dynamic Animation Systems, Inc. [http://www.d-a-s.com/node/36, last accessed June 18, 2013].

National Oceanic and Atmospheric Administration, 2011, Games@NOAA: United States Department of Commerce [http://games.noaa.gov/, last accessed June 20, 2013].

National Oceanic and Atmospheric Administration, 2009, Where the Rivers Meet the Sea: United States Department of Commerce [http://games.noaa.gov/oscar/, last accessed June 18, 2013]. 
National Research Council, 2004, Committee on assessing and valuing the services of aquatic and related terrestrial ecosystems - Valuing ecosystem services-Toward better environmental decisionmaking: Washington, D.C., The National Academies Press, 278pp.

National Research Council, 2011, Learning science through computer games and simulations, Committee on Science Learning, in Computer games, simulations, and education, Honey, M.A., and Hilton, M.L., eds., Board on Science Education, Division of Behavioral and Social Sciences and Education: Washington, D.C., The National Academies Press, 174pp.

Office and Science and Technology in the UK, 2005, FloodRanger: Discovery Software, Ltd., View the World, Ltd. [http://www.discoverysoftware.co.uk/FloodRanger.htm, last accessed June 18, 2013].

Pacific Fishery Management Council, [n.d.], Pacific Fishery Management Council: [http://www.pcouncil.org/, last accessed June 20, 2013].

Pahl-Wostl, C., and Hare, M., 2004, Processes of social learning in integrated resources management: Journal of Community and Applied Social Psychology, v. 14, p. 193-206.

Parker, D.C., Manson, S.M., Janssen,M.A, Hoffmann,M.J, and Deadman, P., 2003, Multi-agent systems for the simulation of land-use and land-cover change-A review: Annals of the Association of American Geographers, v. 93, no. 2, p. 314-337.

Prensky, M., 2001, Digital-game-based learning: New York, McGraw Hill, 442pp.

Saunders, D., and Severn, J., eds., 1999, The international simulation and gaming research yearbook, v. 7: London, Kogan Page, 284 p.

Sawyer, Ben, 2002, Improving public policy through game-based learning and simulation, foresight and governance project: Woodrow Wilson International Center for Scholars, publication 20002-1, [http://www.seriousgames.org/images/seriousarticle.pdf, last accessed June 17, 2013], 35pp.

Shaffer, D.W., 2006, Epistemic frames for epistemic games: Computers and Education, v. 26, p. 223234.

Squire, K., and Jenkins, H., 2003. Harnessing the power of games in education: Insight, v. 3, no. 1, p. 533.

Stoll, C., 1999, High-tech heretic: Reflections of a computer contrarian: New York, First Anchor Books, 240pp.

Susi, T., Johannesson, M., and Backlund, P., 2007, Serious games-An overview: Sweden, University of Skovde, School of Humanities and Informatics, Technical Report HS-IKI-TR-07-001, 28pp.

Trott, K., 2007, Delta reflections-The values of Delta agriculture: A report from interviews with fourteen Delta growers, July 26, 2007, [http://deltavision.ca.gov/Context_memos/Agriculture/Agriculture_Voices_07-26-07.pdf, last accessed June 24, 2013]. 
Tsuchiya, T., and Tsuchiya, S., 1999, The unique contribution of gaming simulation-Towards establishment of the discipline: International Simulation and Gaming Research Yearbook, Vol. 7, London, Kogan Page, p. 46-57.

United States Department of the Army, 2012, America's Army-Home: United States Department of Defense [http://www.americasarmy.com, last accessed May 23, 2013].

United States Department of Education, [n.d.], Creature Control-The Quest for Homeostasis: [http://www.creaturecontrolscience.com/, last accessed June 18, 2013].

United States Department of Justice, 1998, Quandaries: [http://www.oldgames.com/download/3345/quandaries, last accessed June 18, 2013].

United States Department of Transportation, Federal Highway Administration, 2008, Chapter 4. Using Special Techniques to Enhance Participation - Techniques - Publications - Public Involvement Planning - FHWA:

[http://www.fhwa.dot.gov/planning/public_involvement/publications/techniques/chapter04.cfm\#a2, last accessed June 24, 2013].

United States Environmental Protection Agency, 2002, National emission inventory booklet: [http://www.epa.gov/ttn/chief/net/2002neibooklet.pdf, last accessed June 24, 2013].

United States Environmental Protection Agency, 2008, DMR Pollutant Loading Tool | US EPA: [http://cfpub.epa.gov/dmr/adv_search.cfm, last accessed June 25, 2013].

United States Geological Survey, 2007, Facing tomorrow’s challenges-U.S. Geological Survey science in the decade 2007-2017: U.S. Geological Survey Circular 1309, 69 p., [http://pubs.usgs.gov/circ/2007/1309, last accessed June 21, 2013].

United States Geological Survey, 2008, Education Resources: [http://education.usgs.gov/, last accessed June 24, 2013].

Wilensky, U., 1998, Netlogo: Center for Computer Based Learning [http://ccl.northwestern.edu/netlogo/, last accessed June 18, 2013]. 


\section{Appendix: List of Sacramento-San Joaquin Delta Issues}

Issues pertaining to the fish, hazards, storms and climate change, and economic development that include

a. Fish

i. Overfishing (commercial? and recreational)

ii. Fish-spawning area access and conditions

iii. Contamination of fish

iv. Endangered species

v. Affect of salinity on fish populations

vi. Inhibited fish movement

b. Hazards

i. Earthquakes

ii. Floods,

iii. Integrity of levees

iv. Uncertainty of storms and snow runoff

c. Storms and climate change

i. Sea-level rise

ii. Floods (new flood plain information regarding certified levees)

iii. Water availability—reduced snowpack and less spring runoff

iv. More winter flooding

v. Hotter temperatures and effect on agriculture

vi. Less water for irrigation

vii. Encroachment of sea water into delta and effect on water supply and conveyance d. Economic development

i. Population trends

ii. Housing, commercial development, new cities

iii. Needs for infrastructure

iv. Preservation versus development 